Noname manuscript No.

(will be inserted by the editor)

\title{
Design Theory for Generating Alternatives in Public Decision Making Processes
}

Irene Pluchinotta · Akin O. Kazakçi • Raffaele

Giordano · Alexis Tsoukiàs

the date of receipt and acceptance should be inserted later

I. Pluchinotta

LAMSADE-CNRS, PSL Research University, Université Paris Dauphine, Place du Maréchal de Lattre de Tassigny, 75016 Paris, France

E-mail: irene.pluchinotta@lamsade.dauphine.fr

(corresponding author)

A. O. Kazakçi

Centre de Gestion Scientifique, MINES ParisTech, PSL Research University, 60 Boulevard Saint-Michel, 75006 Paris, France

E-mail: akin.kazakci@mines-paristech.fr

R. Giordano

Water Research Institute, National Research Council, Via De Blasio 5, Bari, Italy

E-mail: raffaele.giordano@ba.irsa.cnr.it

A. Tsoukiàs

LAMSADE-CNRS, PSL Research University, Université Paris Dauphine, Place du Maréchal de Lattre de Tassigny, 75016 Paris, France

E-mail: alexis.tsoukias@dauphine.fr 


\section{Introduction}

Governments and public bodies are beginning to involve stakeholders and the general public to a far greater extent than before in the public decision process (Bayley and French, 2008). Public participation is widely documented as being a valuable component of policy making (e.g. Beierle and Cayford. 2002), bringing the problem of facilitating stakeholders' contributions and building collective commitment (Eden and Ackermann, 2013).

Policy making that includes stakeholders offers best practices but also examples of unsuccessful case studies (e.g. Creighton, 2005; Howlett, 2011a; UNDP, 2012, Webler and Renn, 1995). Actors with different stakes, points of view, rationales, and values are brought together to participate in public decision making processes (Fischer et al, 2007). Initially, policy making has been considered to be a linear path from problem definition to options evaluation (Mintrom and Luetjens, 2016). Participation was traditionally reserved for political authorities and external experts (Celino and Concilio, 2011). Indeed, experts' contributions received more attention than local stakeholders' knowledge (e.g. Eden and Ackermann, 2004; Ostrom, 1990). However, thanks to the increasing awareness of the complexities facing the public sector, this view has been challenged (see recently De Marchi et al, 2016, Tsoukiàs et al, 2013). Instead of a rational selection among given policy alternatives, public decision making becomes the result of a collaborative process (Nogueira et al, 2017; Sabatier, 2007). As such, the development of a shared understanding among all involved actors is a prerequisite for the successful implementation of a collaborative process $(0 \mathrm{ppl}, 2017)$.

Many academic studies have investigated participation, suggesting that all modes of public participation can potentially benefit society (e.g. Beierle, 2002; Daniell et al, 2010; French et al, 2007; Gregory et al, 2005, Lavin, 2010). Furthermore, stakeholders participation has been investigated in the field of Decision Analysis where stakeholders' problem frames, knowledge and preferences are considered pivotal elements of the policy making process. For interested readers (Ferretti et al, 2019), soft systems methodologies and problem structuring methods (Checkland, 2000, Pollock et al, 1994, Rosenhead, 2006), group modelling (Vennix, 1996), system dynamics (Sterman, 2000), stakeholder strategic management (Ackermann and Eden, 2011, Freeman, 2010), meta-planning knowledge management (Wilensky, 1981), strategic choice approach (Friend and Hickling, 1987), collaborative decision making approach (Zarate, 2013).

Although the specialized literature recognises the use of public participation necessary, it expresses doubts on the used methodologies (e.g. French and Bayley, 2011; Rowe et al, 2005). Ostrom (2010) highlights the deficiency of adequate methodologies for supporting public decision making processes with multiple stakeholders. Specifically, most approaches about participation are being used to draw stakeholders into the process of deciding between different options, but not on their generation (Ferretti et al, 2019). Indeed, the mainstream Decision Analysis literature focuses on how to "choose" an alternative without considering how these can be established (Colorni and Tsoukiàs, 2018).

Meaningful participation requires stakeholders engagement into all the phases of the process (Marttunen et al, 2013, which is not necessarily the case for most methods aimed at supporting participation and public policy making. Firstly, policy making often incorporates stakeholders late in the process, after the problem definition has occurred and alternatives have been already defined, raising the risk of the consultation being construed as a formality, limiting the ability of stakeholders to seriously inform the process (Mintrom and 
Luetjens, 2016). Secondly, most collaborative decision making procedures are perceived to be unproductive in terms of efficiently utilizing the participants' time and effectively achieving the policy objectives Adla et al, 2011). Lastly, policy design has long been seen as a component of policy development without any operational characteristic (Howlett, 2011a; Lynn and Gould, 1980, Schneider and Ingram, 1997). For instance, the Strategic Choice Approach, as a method facilitating collaborative processes about complex decision problems (Friend et al, 1974), improves the understanding of inter-organisational decision processes in various public policy domains and has been successfully used in supporting public policy making (e.g. Friend and Hickling, 1987; Norese et al, 2015). However, it does not explicitly support the design of policy alternatives, at least not using a formal theory and a replicable procedure. Thus, the efforts for structuring problems and working towards decisions are not combined with an in-depth designing.

Stakeholders involvement in policy making increases the need for effective policy design processes (Fischer, 2000). However, there seems to be a relatively small literature on how to formally design policy alternatives (Howlett, 2014). Experience suggests that well-structured and formalized methods for policy design are needed to integrate knowledge from different sources, allowing transparency of the process (Renn, 2006). Moore (1995) talks about the structured inclusion of different stakeholders' knowledge, in order to unleash creativity and conceive new solutions. This should represent the starting point of an effective and innovative design process (Tavella and Franco, 2015). Within this context, there is a demand for methodologies aiming to support the policy makers and relevant stakeholders during the design of alternatives within the policy making process (Ferretti et al, 2019).

In this paper, we are interested in introducing (and exploring) the operational role of design theory. Design theory highlights the value of early stakeholders engagement (e.g. Buchanan, 1992, Dorst and Cross, 2001, Liedtka et al, 2013, Rowe, 1998), challenging some current mainstream approaches of policy making (Mintrom and Luetjens, 2016). Specialized literature in design theory already exists (e.g. Agogué and Kazakçi, 2014), offering a range of methodologies for products development (Brown, 2008). The research reported in this paper uses the derived knowledge, methods and expertise to understand what "design" means in a policy making context. It aims to contribute by creating an innovative approach for the formalization of the policy design process. It claims that design theory can improve the policy design process and that Concept and Knowledge (CK) theory (Hatchuel and Weil, 2002) can be a suitable framework for the innovative design of policy alternatives.

The paper is structured as follows. After the present introduction, section 2 depicts the mainstream approaches to policy design. Sections 3 illustrates the design theory framework. Section 4 describes the proposed methodology while section 5 and 6 discuss the case study, the obtained results and the lessons learned. Concluding remarks are reported in section 7 .

\section{Policy design}

Public policies are abstract objects introducing a portfolio of interrelated actions, reflecting the policy makers' efforts to address public and societal problems (De Marchi et al, 2016). This set of actions aims to achieve a set of interconnected policy goals within a period of time (Elmore, 1987; Hand, 2012), through the influence on individual and collective decisions (Bemelmans-Videc and Vedung, 1998). 
Policy makers create policy alternatives (Howlett, 2014). Thus, policy design is a critical step that enables the pursuit of innovation (Lasswell, 1956) and the formulation of effective policy alternatives (Howlett et al, 2015). "The invention of policy proposals" (Lasswell, 1971) is essential to the development of policies inasmuch an integral part of the public decision making process (Wildavsky, 1979). A worthy policy design process has a preponderant impact on the quality of the policy alternatives being considered.

However, no significant research has examined the formal design processes for the generation of policy alternatives thus far (Ferretti et al, 2019, see). Bobrow (2006) underlines that policy design is surprisingly understudied in the policy analysis literature. The roots of policy design studies can be found in the policy science literature since the 1950 s, however it has received significant attention only in the past three decades (e.g. May, 1981, 2003) (see figure 11).

\section{Figure 1 approximately here}

In his early works on public policy making, Lasswell (1954) stated that the understanding of the policy instruments available is an important feature of both policy formulation and implementation. In the 1970s, policy design processes focused on the evaluation of the economic impact of policy instruments (e.g. taxes and subsidies), in order to support policy makers in considerations of policy effectiveness (Mayntz, 1979, Sterner. 2003).

Policy design research was developed during the 1980s and 1990s, involving interdisciplinary literature. Specifically, the policy design literature shifted towards understanding design both as process and outcome. Several researchers and practitioners wrote about problem formulation, policy instrument choice and policy design outcomes (e.g. Howlett, 2014, May, 1991; Weimer, 1992). In the 1980s, the policy research was interested in the links between implementation failures and policy success (Mayntz, 1981, O’Toole, 2000). In the early 1990s the focus was the ex-post evaluation of policy outcomes impacts (Bobrow and Dryzek, 1987). Furthermore, an interdisciplinary approach combined economic and law studies in order to focus on policy outputs and governmental processes. On the one side, law studies analyzed how regulations mediated the delivery of goods and services, and how formal processes of rule-making led to policy (Keyes, 1996). On the other side, management studies investigated the links between administrative systems and implementation modes (Lowi, 1985, Peters and Pierre, 1998). Specifically, both Bardach (1977) and Salamon (1981) argued that the early policy studies analyzed policy in terms of "problems" rather than in terms of "instruments of government action" and "techniques of social intervention". A specific policy design literature appeared in the mid-1980s through a systematic study of policy instruments (Howlett, 2014). Policy analysts' attention shifted from practice to theory, classifying policy instruments in order to identify the reasons of their use (Bressers and Klok, 1988, Hood, 1986) and to improve both policy design and outcomes (Linder and Peters, 1984; Woodside, 1986). In the late 1990s, policy design literature focused on instrument selection. It aimed to systematically assess the development of optimal policies by using mixed strategies, moving away from the single instrument studies of earlier works (Gunningham et al, 1998: Howlett. 2004). This period was marked by the dispersion of policy design scholars in specific fields such as economics, and environmental studies (Del Rio et al, 2010: Howlett and Lejano, 2013).

Recently, attention shifted from centrality of authority to the collaborative governance, involving nongovernmental actors, among others (Howlett, 2011b). Policies are seen as the outcome of a decentralized process, involving the actions of several public and private stakeholders. As a result, the implemented policy design 
practices became increasingly participatory and consultative in nature (e.g. Alshuwaikhat and Nkwenti, 2002). They replaced previous top-down processes dominated by government analysts with bottom-up ones. The demise of policy design research could be associated with the change in demand for more collaborative governance (e.g. Hysing, 2009, Levi-Faur, 2012).

Under a Decision Sciences perspective, Simon (1954) suggested attention to procedural rationality in wicked situations such as public policy making, i.e. when substantive rationality is impossible or inappropriate. He stressed the importance of design processes to support decision making based on human deliberation. Procedural rational approaches are based on the discovery of new alternatives, i.e. in such situations, it is not a question of comparing options that are known for developing acceptable solutions (Pidd, 2004). The identification of a new set of alternatives intended to be a collaborative process for the resolution of conflicts between antagonistic or bounded stakeholders.

Lastly, policy design has been investigated as depending on the design of products and services (Alford, 2009). Considering that design thinking is essential in product development (Brown, 2009, Martin, 2009), traditional public policy making contemplates policy development from a design theory prospective (e.g. Howlett, 2011a, Lynn and Gould, 1980). Whilst policy making constitutes a design activity, it is yet to be discussed in design terms (Mintrom and Luetjens, 2016).

The lack of methodologies for the generation of policy alternatives can be managed by introducing design theory based approaches. This paper aims to contribute to the establishment of a methodology by formalizing the process of innovative design of policy alternatives. For this reason, we consider important to analyse the design theory literature in the next section.

3 From rule-based design to innovative design: the genesis of the $\mathrm{C}-\mathrm{K}$ theory

Design is defined as a process of changing an existing situation to a desired one (Simon, 1969), through the conception and description of an idea (Alexander. 1982). The present section aims to present the key elements of the design theory in order to clarify its possible use for the policy design process.

The early design theory is characterized by the desire to understand design as a systematic process, based on objectivity and rationality: design tasks are broken down into simplified sub-tasks (Alexander 1964) through abstract mathematical notation (Archer, 1963, 1970) within repeatable procedures (Forester, 1999). The main focus of early design theory is the attempt to incorporate scientific knowledge and engineering techniques into a rational design process (Bayazit, 2004). It generates adapted solutions to well-formulated requirements within a systematic reasoning (Elmquist and Segrestin, 2009). For instance, the Axiomatic Design approach (Suh, 1990) characterizes the quality of the design process through a two dimensional matrix analysing types of parameters describing a given object (Agogué and Kazakçi, 2014). The so called rule-based design methodologies are based on the "dominant design" of objects, helping firms to face the growing need for a mass production around well-identified objects (Elmquist and Segrestin, 2009). According to Utterback and Abernathy (1975), the dominant design, identifies key features and attributes that become standard over the evolution of the industrial dynamics (see the key contribution of Pahl and Beitz(1984).) Consequentially, conceptual breakthroughs are rare (Hatchuel et al, 2015). The rule-based design is unable to describe objects outside their dominant patterns, moving 
around its known and stable characteristics and design activities are structured around known performance parameters, establishing of optimized product lines process (Agogué and Kazakçi, 2014).

On the other side, the modern generation of design theory explores "disruptive innovation challenges", modifying the characteristics of objects (Hatchuel et al, 2008). In order to provide breakthrough innovations, the properties of the object are challenged. The attributes of products are questioned, and new expertise may need to be developed (Elmquist and Segrestin, 2009). With a purpose to meet such challenges, Hatchuel and Weil (1999) aimed to analyse the mechanisms of innovative design through the development of the Concept-Knowledge (C$\mathrm{K})$ theory where the design is defined as a generative process which something unknown can intentionally emerge from what is known. From the beginning (Hatchuel and Weil, 2002), the features of C-K theory were recognized as being unique for describing creative reasoning in the design process of generating alternatives (Sharif Ullah et al, 2012). Over the last few years, C-K theory has gained a growing academic and industrial interest (Agogué and Kazakçi, 2014). C-K is a theory of reasoning for innovative design situations, overcoming the limits of traditional design theory (Hatchuel et al, 2015) and creativity methods (Kazakçi and Tsoukiàs, 2005). It provides researchers and practitioners with a framework to describe and analyse innovative design processes for the generation of alternatives. Indeed, C-K theory goes beyond two traditional design axioms: i) the design reasoning is arranged on a stabilized set of functions (i.e. rule-based design); ii) creativity in design is interpreted as an uncontrollable process of idea generation (Hatchuel et al, 2004).

$\mathrm{C}-\mathrm{K}$ theory is based on the distinction between two expandable spaces: a space of Concepts (C-space), and a space of Knowledge (K-space). The process of design is thus defined as the co-evolution of C-and $\mathrm{K}$ - spaces through four types of independent operators $(C \rightarrow C, C \rightarrow K, K \rightarrow C, K \rightarrow K)$. According to Hatchuel and Weil (2003), the K-space is a space of propositions that have a logical status (i.e. "true" or "false") for a designer. Whereas, the C-space is a set of propositions describing an object, that has no logical status in the current K-space: when a Concept is formulated, it is an "unknown" entity, and it is impossible to prove that it is a proposition of the K-space. A Concept expresses a group of properties qualifying a given entity, such as " $\mathrm{C}$ : there exist an object $x$ with the properties $p_{1}, p_{2}, \ldots, p_{n}$ " (Agogué et al, 2014). Therefore, within the C-K theory, the design activity is defined as the process by which a Concept generates other Concepts or is transformed into Knowledge, i.e. the co-evolution of the $\mathbf{C}$ - and $\mathbf{K}$ - spaces (Le Masson et al, 2014). Figure 2 illustrates an examples of how the operators could be structured.

\section{Figure 2 approximately here}

Within a given design process every C-space has a strong dependency on the related K-space. Every element and possible expansion in the C-space relays on the structure and contents of the Knowledge base (Hatchuel et al, 2004). Once the designer imagines something new, he/she creates new concepts - expanding the C-space and he/she activates simultaneously new knowledge - expanding the K-space. These expansions are complementary: a new knowledge provokes the identification of new concepts and elaboration of new concepts results in the search process to acquire new knowledge. Thus, C-K theory proposes a formal framework for structuring the complementary expansions, supporting the generation of new concepts.

Building a C-K model (Figure 3) with different design paths and various levels of mastery of the K-space, leads to the definition of the C-space with the existing dominant design of the object and possible pathways expansion (i.e identification of new alternatives) (Agogué et al 2014). Within a C-K model, the C-space, is structured 
as a tree including three different types of C-paths: i) describing the attributes of the existing dominant design related to validated knowledge (items in light grey in Figure 3, ii) characterizing concepts that are reachable and attainable using existing knowledge or its recombination (items in mid grey in Figure 3 and iii) outlining new alternatives, through the $\mathrm{C}$-space expansion combined with the further exploration of the $\mathrm{K}$-space (dark grey in Figure 3. This evolving structure helps to identify fixation effects and lack of information that limit the ability to generate novel ideas.

\section{Figure 3 approximately here}

C-K theory offers a formal framework, providing a definition of the design process independent of any domain, where creative thinking, learning process, knowledge structuring, knowledge sharing, and innovation principles are not external phenomena but are the central core of the theory itself. Therefore, $\mathrm{C}-\mathrm{K}$ theory helps to analyze the limits of traditional methods of collective creative design (Hatchuel et al, 2015). Methods of harnessing group creativity, such as more or less sophisticated brainstorming, tend to lead to a consensus with very few breakthroughs. On the other hand, potential well-structured creativity task forces are not able to follow the creative breakthrough due to the limited size of the Knowledge base or the lack expert inputs. C-K theory is used to overcome these constraints while creating a formal framework for collectively innovative design processes (Hatchuel and Weil, 2009).

\subsection{The KCP tool for innovative collective design activities}

According to the $\mathrm{C}-\mathrm{K}$ theory theoretical framework, the design reasoning is interpreted as the co-evolution of the $\mathrm{C}$ - and K-spaces. This co-evolution allows to formally describe the learning process (K-space expansion) and to decode the way in which new knowledge supports the generation of new concepts (C-space expansion). Operationalizing the $\mathrm{C}-\mathrm{K}$ theory, the KCP methodology (i.e. $K$ for knowledge, $C$ for concepts and $P$ for proposals) was developed to manage collaborative design process, where many participants are involved (i.e. experts, users, researchers, engineers, designers, customers, ...) (Hooge et al, 2016). The KCP, described in detail by Hatchuel and Weil (2009) and Agogué et al (2014), is composed by three phases briefly outlined below:

K phase. K-sessions aim to collectively build and share the available knowledge about a given object under design. They consist of several days of seminars in which experts make presentations. The knowledge-exchange activities can be both internal to the design team (i.e. sharing internal knowledge usually compartmentalized in different departments and unshared) or external involving experts. This phase does not contain any creative activity and allows to open up new perspectives in a field of knowledge with an exploration scope. At the end of this phase, the team is able to (re)structure the K-space, identifying possible polysemy and ambiguity, isolating conventional forms of design to highlight paths of possible breakthrough. The K-phase can reveal some weaknesses in the initial individual $\mathrm{K}$-space, in order to prepare for future C-space expansion.

C phase. The C-phase consists of a series of generative sessions during which the design team is involved in a "conceptual building effort". It aims to activate and encourage unexpected concepts-exploration. The output of the C-phase are detailed proposals of innovative concepts. $\mathrm{C}$-K theory differs from creativity techniques such as brainstorming in the way that disruptive paths are explored through pre-defined concepts that guide the 
creativity session (i.e. contrary to brainstorming, relying on free divergence, the C-phase manages a divergence phase).

P phase. The last phase consists in synthesizing the outcomes of both the $\mathrm{K}$ - and the $\mathrm{C}$ - phases into a structured innovative design strategy. It focuses on the identification of different design paths. The P-phase aims to engage actors at all levels, by making them informed and aware of learning issues. The P-phase helps the decisionmakers, to assimilate the structure of the innovation field, to keep the variety of alternatives and avoid to focus on one apparently dominating solution.

In conclusion, the KCP methodology has been successfully used in a variety of contexts ranging from large companies in the transport sector to agricultural cooperatives or firms from the energy industry (Agogué et al, 2014). It is lacking however, any application with respect to the more complex issue of public policies. To this end, the paper proposes a new participatory tool for the innovative design of policy alternatives, based on the KCP and within the $\mathrm{C}-\mathrm{K}$ theoretical framework. The paper introduces and explores the possible role of design theory in the policy making process. There are a practical and a theoretical reason: how can one practically employ the KCP methodology for policy design? Does C-K theory need to evolve and adapt with respect to policy design? A pilot case study aiming to extend the $\mathrm{KCP}$ methodology in the area of policy design is presented in the following sections.

\section{Policy-KCP: a systematic generative mechanism for the design of policy alternatives}

The Policy-KCP (P-KCP) is a participatory tool for the innovative generation of policy alternatives. It is a C-K theory drive tool, adapted to the design of abstract objects such as public policies. The P-KCP aims to formalize the innovative design of policy alternatives within a public decision making process. A formal methodology is developed allowing systematic design of public policies that can go beyond traditional policy alternatives. The PKCP supports the creation of a shared artefact (Ostanello and Tsoukiàs. 1993), further motivating stakeholders engagement and commitment to a participative policy making process. The steps of the $\mathrm{P}-\mathrm{KCP}$ participatory tool are described in the following.

Policy-Definition phase (P-D phase). The preliminary phase aims to determine key topics and relevant expertise, underpinning the development of policy alternatives. It identifies the relevant stakeholders and supports the initial problem formulation of the policy issue under analysis. Firstly, the policy design management team defines the list of suitable participants. In order to support the stakeholder engagement process, it is important that the participants are chosen based on their ability to inform the process and to be knowledgeable about it. In participatory approaches, stakeholder analysis has been seen as a way of generating information on the relevant actors to understand their behaviour, interests, agendas, and influence on decision making processes (Brugha and Varvasovsky, 2000, Reed et al, 2009). Usually, in order to minimise the selection bias and the marginalization of stakeholders (Ananda and Herath, 2003) a top-down stakeholder identification practice, namely "snowballing" or "referral sampling", is implemented (e.g. Harrison and Qureshi, 2000, Reed et al, 2009). At the end, the stakeholder analysis leads to an in-depth characterization of the relevant actors, their objectives (Lienert et al, 2013) and the relationships between them (Giordano et al, 2017b). 
Secondly, the collected knowledge is structured in the initial problem formulation. In public decision making processes, the problems are often complex and wicked (De Marchi et al, 2016, Rittel and Webber, 1973) and stakeholder groups have different perspectives that need to be incorporated in a participatory process (Marttunen et al, 2013). Differences in problem framing and understanding are unavoidable, deeming ambiguous problem definitions (Santoro et al, 2019). On the one hand, a diversity in frames can enhance the co-production of knowledge, offering opportunities for innovative solutions. On the other hand, the presence of ambiguity can be a source of discrepancies or conflict in a group, hampering the implementation and/or reducing the effectiveness of the policy (Giordano et al, 2017a). Thus, preliminary interviews allow to define an initial problem understanding, underlining the differences between the stakeholders' points of view.

The expected outcomes are: i) a preliminary synthesis of the state-of-the-art knowledge, ii) the stakeholder analysis with the depiction of objectives and values, and iii) a preliminary analysis of the different problem understandings according to the stakeholder's perceptions.

Policy-Knowledge phase (P-K phase). The aim of this phase is to reach a collective problem formulation agreed upon by all the involved participants. This is accomplished by gathering missing information and building a comprehensive summary of current knowledge about the policy issue under consideration. Thus, the P-K phase provides the creation of a shared base of knowledge supporting the following generative phase, i.e. P-C phase. The management team combines the outputs from the stakeholders analysis and the initial problem formulation with scientific literature studies, available data, emerging technologies, best practices, current policies, etc. Afterwards, individual meetings with stakeholders complete the problem formulation stage. The individual meetings are organized as semi-structured interviews, where participants' opinion and knowledge concerning the specific policy problem is investigated. Interviewees are free to share their personal knowledge about the given topic. A report of each interview is validated with the interviewed.

This phase supports the building of the overall K-space combining the individual (intermediary) K-spaces, in order to reach a common understanding between each viewpoint. It allows to: i) clarify the existing knowledge, identifying also missing studies, models, and action plans; ii) integrate new stakeholders' views into the initial problem formulation; iii) identify potential barriers or preconditions to work with stakeholders; iv) analyze what competencies stakeholders need before the generative process starts in terms of motivation, knowledge, and practical expertise, in order to be able to effectively participate to the P-C phase. The expected outcomes are: i) a summary of the complete state-of-the-art knowledge on the case study and policy issue under analysis, ii) an improved and detailed stakeholder analysis, iii) the definition of the common problem formulation including the individual points of view and iv) the identification of the dominant design concerning the traditional policy alternatives represented via a preliminary $\mathrm{C}$-tree model. At the end of the P-K phase, the document summarising the complete K-space is shared with all the participants in order to prepare them for the following phase.

Policy-Concepts Generation phase (P-C phase). The aim of the P-C phase is to generate policy alternatives using the $\mathrm{C}-\mathrm{K}$ theoretical framework. It consists of one-day generative workshop with a group of participants and it is divided in four steps. Firstly, the common problem formulation is shared, discussed and validated in order to build a common knowledge ground and a collective shared problem formulation for the generative workshop. Secondly, the preliminary C-tree is explained to all the participants. Afterwards, the participants are divided into heterogeneous groups, in order to collectively evaluate and discuss the elements representing the policy dominant 
design and to suggest the expansions of the C-tree. During this step, each group needs to agree upon the evaluation of the alternatives and C-expansion, leading to a facilitation of a "local" process of defixation. Lastly, a general discussion on the group activities is concluding the workshop, as starting point for the participatory learning process.

The $\mathrm{C}$-space allows to illustrate various alternatives as concepts connected to the initial concept (C0) thanks to the tree-like structure. It represents the map of all possibilities where alternatives are broken down and represented in the form of a concepts-tree. The tree structure highlights the dominant design and improves the search among alternatives branches, thus designs. The C-tree for the innovative design of policy alternatives displays different exploration paths. Figure 3 shows an example of C-tree (Agogué et al, 2014). The left paths describe the genealogy of known objects, i.e. the hierarchy of attributes stabilized in the dominant design. The central branches outline the first C-expansions allowed by the incremental addition of knowledge or the re-organization of existing K-space. Finally, the right side of the C-tree displays the expansions leading to innovative policy alternatives, which are not explored in the K-space yet.

Policy-Project phase (P-P phase). The P-P phase uses the K-space and the C-tree generated in the previous steps, to build a set of policy recommendations, including the innovative set of policies alternatives. Similarly to the KCP approach, an expert team is involved in this phase to test feasibility of the policy alternatives identified and to evaluate them. Considering the different phases of a decision-aiding process (Tsoukiàs, 2007), the P-P phase supports the decision-making process by considering the whole range of possible methodologies for the evaluation of alternatives.

The developed P-KCP participatory tool to formally support the design of policy alternatives has been applied to a pilot case study concerning an environmental policy design problem described in the following section. The pilot case study focuses on the generation of policy alternatives (P-D, P-K and P-C phases) and the possible contribution of its outputs to a following evaluation phase (P-P phase).

\section{The groundwater protection policy within the agricultural sector of the Apulia Region (southern Italy)}

The purpose of this section is to illustrate the implementation of the $\mathrm{P}-\mathrm{KCP}$ tool (described in section 4) for the innovative generation of policy alternatives in a pilot case study. It is worth underlining that the alternatives' evaluation represents the subsequent phase of the decision aiding process (Tsoukiàs, 2007). For this reason, this paper details the alternatives' design phase, i.e. how to build the C-space and the related K-space. The case study discusses the groundwater protection policy and water management within the agricultural sector of the Apulia Region (southern Italy).

\subsection{Case study description}

The area is located in the north of the Apulia Region (southern Italy) and is characterized by the combined use of surfacewater (SW) and groundwater (GW) for irrigation. The strong GW dependency of the agricultural sector and consequential overexploitation generates social and environmental problems. Specifically, the Capitanata Irrigation Consortium (IC) provides SW management, ensuring an adequate technical and administrative assistance to 
farmers (Giordano et al, 2015). The SW annual availability depends strictly upon weather conditions and rainfall patterns, in an area characterised by recurrent drought events. The Regional Authority needs to protect GW quality and at the same time to preserve high productivity standards for the agricultural sector. In 2009 the Regional Authority implemented the Water Protection Plan, in order to significantly restrict the GW use (according to the European Water Framework Directive, CEE 2000/60).

Based on a traditional policy design approach, this policy was defined without considering the potential impacts on the other stakeholders (i.e. farmers and IC) and it caused strong conflicts (Giordano et al, 2013). The policy resistance mechanisms mainly occurred due to the economic damages to the agricultural sector, highly dependent on the water-demanding crops and irrigation practices (Giordano et al, 2017a). On the one side, the IC has to deal with the water shortage and with the farmers' water requests. It uses an increasing pricing strategy (based on the Water Protection Plan), defining two different price thresholds for the SW: the base water supply volume $\left(0.12 € / \mathrm{m}^{3}\right.$ for $\left.2050 \mathrm{~m}^{3} / \mathrm{ha}\right)$ and the additional water supply volume considerably more expensive $\left(0.36 € / \mathrm{m}^{3}\right.$ for 2050-4000 $\mathrm{m}^{3} / \mathrm{ha}$ ). In the IC's problem understanding, this policy would force farmers to reduce the irrigated areas and/or to select less water demanding crops, without considering the GW alternative (Ferretti et al, 2019). On the other side, each farmer maximizes her/his profits by choosing the crop plan with regard to the quantity of available water (i.e. SW and GW) and the hectares of arable land owned. The base water supply volume is not adequate to cover the water request. Within this situation, each farmer can choose between two alternatives: paying for the additional water supply volume (sold by the IC) or using the GW, a cheaper (approximately 0.19 $€ / \mathrm{m}^{3}$ ) and easily accessible resource. Thus, the use of GW is restricted by the Water Protection Plan but the price of the additional water volume is higher than the price of GW withdrawal. Even if the GW quality is lower than the water managed by the IC, farmers tend to prefer the use of GW. The farmers perceive the price for the additional water volume as unsustainable (Ferretti et al, 2019). Therefore, they use the base water supply volume, combined with the GW for the remaining water demand. A detailed description of the case study can be found in Giordano et al (2017a) and Pluchinotta et al (2018).

Given this context, the P-KCP tool aims: i) to allow a collective and participatory discussion on the water management issue, in order to reach a shared understanding of the different problem framing; ii) to contribute to the conflicts mitigation and to the renewed understanding of the problems by all parties; iii) to ensure a better participation of all the stakeholders and integration of their knowledge, in order to overcome the limits of the traditional methodologies; iv) to suggest novel alternatives for the GW protection policies and water management strategies within the agricultural sector.

From a methodological point of view this paper aims: i) to test and validate the effectiveness of a C-K based tool for the innovative design of policy alternatives within the policy cycle; ii) to showcase a proactive approach, supporting research and proposing a "best practice" participatory processes as an example to improve the policy design process.

5.2 The Policy-KCP participatory tool for the innovative generation of policy alternatives

P-D phase. During the pre-workshops activities, the policy design management team outlined a first list of relevant participants, determining which stakeholder is involved in or affected by the policy issue under investigation. 
As stakeholders were considered all the individuals, groups, or institutions related to the policy problem with common or conflicting objectives. Further details on the identified stakeholders and their role are showed in table 1 . To make sure that all relevant stakeholders were included in the process, the selection process starts with the identification of the stakeholders mentioned in official documents, reports, and institutional protocols. Thereafter, preliminary interviews with experts and institutional actors allowed to widen the set of stakeholders to be involved (examples of questions are: which stakeholder should be involved in the policy design process and in the P-KCP workshop? Why? What is your viewpoint concerning the policy goal? What are the other stakeholders' viewpoints? etc.) The profile of each possible participant was created including objectives and perspectives of the GW management problem. Moreover, the relationships with other stakeholders were investigated in order to detect conflictual situations (using the Interaction Space model defined in Ostanello and Tsoukiàs (1993) and applied in Giordano et al (2017a). Previous research activities on the same case study supported this preparatory phase (e.g. Portoghese et al, 2013; Giordano et al, 2015; Pluchinotta, 2015)). The D-phase allowed an initial definition of the problem formulation, i.e. reducing the GW dependence, ensuring a suitable water volume for the agriculture $(\mathrm{C} 0)$.

P-K phase. The P-K phase supported the identification of the common knowledge on the GW protection and SW management problem, including the quali- quantitative state of GW aquifers and the analysis of the different stakeholders' problem framing. The knowledge elicitation activities were carried out by integrating scientific and technical evidences available in literature with expert and local knowledge (Fischer, 2000, Schon, 1983), according to participatory work principles. After the first round of interviews of the P-D phase, a second extended round of semi-structured interviews was carried out. The interviews inspected several topics such as the water management strategies, the peculiarities of the IC's SW management, the main characteristics of the agriculture sector and farmers' behaviours, the issues related to field controls, the known effects of the high irrigation practices on the GW aquifers state, etc. Due to the stakeholders' time constraints, K sessions and common knowledge sharing seminars were not possible (see section 3.1). Nevertheless, the design management team interacted and collaborated with all the participants along all the phase. Scientific knowledge available in literature was combined with expert knowledge elicited the interviews and thanks to participatory processes performed previously on the same area (e.g. Pluchinotta et al, 2018; Giordano et al, 2017a). All the information collected was written and distributed to all the involved stakeholders, developing the first version of the P-K space. During this phase, participants started learning from other stakeholders' knowledge and realizing missing knowledge elements thanks to the P-K space. The knowledge sharing process supporting the alignment of the different stakeholder's perception of the policy issue (i.e. the social aspect of the K-sessions) was organized as the starting point of the C-phase (i.e. a general discussion at the beginning of the one-day generative workshop). Lastly, in this phase, students supported the design management team, accelerating the time-demanding task of GW management best-practices identification. The students attending the 2017 master of ENSAM-Mines ParisTech, trained with the $\mathrm{C}-\mathrm{K}$ principles, enriched the $\mathrm{P}-\mathrm{K}$ space with information about innovative irrigation techniques and sustainable water management examples.

P-C phase. Similarly to the traditional KCP methodology, the P-C phase includes the generation of different design paths within the $\mathrm{C}$-tree. Further details on the stakeholders involved in the one-day generative workshop are shown in table 1 . Using a color code, figure 6 shows the whole C-tree: i) the branches describing the 
attributes of the existing dominant design of known policy alternatives are colored in black, ii) the ones in blue indicate attainable policy alternatives use existing knowledge or a combination of K-space subsets (i.e. policy alternatives used in best practices of comparable case studies), and iii) the paths in green represent breaking new ground policy alternatives, requiring the expansion of the $\mathrm{K}$-space in order to enlarge the C-space.

Table 1 List of participants involved in the one-day generative workshop

\begin{tabular}{lll}
\hline Stakeholders & $\begin{array}{l}\text { Number of } \\
\text { involved }\end{array}$ & Role \\
& Stakeholders & \\
\hline Farmers - Small scale & 4 & Water user \\
Farmers - Large scale & 3 & Water user \\
Consortium of Capitanata - Technical & 3 & Local water management authority \\
Consortium of Capitanata - Political & 3 & Local water management authority \\
Regional Authority & 1 & Regional political authority \\
River Basin Authority & 2 & Regional technical authority \\
Expert - IRSA-CNR & 1 & Water management and governance \\
Expert - IRSA-CNR & 1 & Water balance physical models \\
Expert - CIHEAM & 1 & Agricultural land/water governance \\
Expert - University of Bari & 1 & Agricultural economy \\
Management team & 1 & C-K theory expert \\
Management team & 1 & Decision science expert \\
Management team & 1 & Case study expert \\
Assistants & 1 & - \\
Observers & 2 & - \\
\hline & & \\
\hline & &
\end{tabular}

Table 2 lists the elements of the C-tree (figure 4), underlining the concepts hierarchy and the preliminary stakeholders' interest in exploring certain alternatives (i.e. number of stakeholders considering relevant the alternative at the beginning of the process).

The expected output of the P-C phase is to frame possible innovative alternatives to be explored in the following P-P phases. Through the generative workshop, a collective problem understanding and formulation have been settled and the set of policy alternatives have been analysed and improved. During the one-day generative workshop, the process of designing policy alternatives was supported and managed accordingly to the C-K principles of innovation management.

Table 2: List of policy alternatives generated in order to reduce the GW dependence, ensuring a suitable water volume for the agricultural sector $(\mathrm{C} 0)$

C0 To reduce the GW dependence, ensuring a suitable water volume for the agriculture

\begin{tabular}{lll}
\hline ID Policy alternatives & Number of & Status \\
& stakeholders & \\
& interested & \\
& in exploring \\
& the alternative & \\
\hline
\end{tabular}




\begin{tabular}{|c|c|c|c|}
\hline $\mathrm{C} 1$ & Reduction of water resource use & & \\
\hline $\mathrm{C} 1.1$ & Not modifying the Farmers' water requirements & & \\
\hline C1.1.1 & Surface water management & & \\
\hline C1.1.1.1 & Pricing strategy & - & Dominant Design \\
\hline C1.1.1.1.1 & Pricing strategy for everyone & 1 & Dominant Design \\
\hline C1.1.1.1.1 & Pricing strategy for overconsumers & - & Dominant Design \\
\hline C1.1.1.2 & Pricing strategy and controls & - & Dominant Design \\
\hline C1.1.1.2.1 & Direct controls & 2 & Dominant Design \\
\hline C1.1.1.2.1.1 & Direct controls using Acqua Card & - & Dominant Design \\
\hline C1.1.1.2.1.2 & Direct controls on the fields & - & Known \\
\hline C1.1.1.2.2 & Indirect controls & 1 & Dominant Design \\
\hline C1.1.1.2.2.1 & Indirect controls from declared crop plan & - & Known \\
\hline C1.1.1.2.2.2 & Indirect controls using GIS & 1 & Known \\
\hline C1.1.1.3 & Improving the water distribution system & 1 & Dominant Design \\
\hline C1.1.1.3.1 & Improving the water supply infrastructure & 2 & Dominant Design \\
\hline C1.1.1.3.2 & Extending the water supply infrastructure & 2 & Dominant Design \\
\hline C1.1.1.4 & Improving drought management system & - & Unknown \\
\hline C1.1.1.4.1 & Drought early warning system & 7 & Unknown \\
\hline C1.1.2 & Ground water management & & \\
\hline C1.1.2.1 & Concessions & - & Known \\
\hline C1.1.2.1.1 & Concessions - wells & - & Known \\
\hline C1.1.2.1.2 & Concessions - water volume & - & Known \\
\hline C1.1.2.2 & Pricing strategy & - & Known \\
\hline C1.1.2.2.1 & Pricing strategy for everyone & - & Known \\
\hline C1.1.2.2.2 & Pricing strategy for overconsumers & - & Known \\
\hline C1.1.2.3 & Pricing strategy and controls & - & Known \\
\hline C1.1.2.3.1 & Direct controls & - & Known \\
\hline C1.1.2.2.1.1 & Direct controls using flow meters & - & Known \\
\hline C1.1.2.2.1.2 & Direct controls on the $G W$ aquifers & 2 & Known \\
\hline C1.1.2.3.2 & Indirect controls & 4 & Known \\
\hline C1.1.1.3.2.1 & Indirect controls from energetic consumption & - & Known \\
\hline C1.1.1.3.2.2 & Indirect controls from declared crop plan & 1 & Known \\
\hline C1.1.1.2.2.3 & Indirect controls using GIS & 4 & Known \\
\hline C1.1.2.4 & Water market between users & 2 & Unknown \\
\hline C1.1.2.5 & Shared management of GW aquifer & 10 & Unknown \\
\hline $\mathrm{C} 1$ & Reduction of water resource use & & \\
\hline $\mathrm{C} 1.2$ & Modifying the Farmers' water requirements & & \\
\hline C1.2.1 & Efficient irrigation techniques & 3 & \\
\hline C1.2.1.1 & Rainbird irrigation & - & Known \\
\hline C1.2.1.2 & Drip irrigation & - & Known \\
\hline C1.2.1.3 & Sub irrigation & 2 & Known \\
\hline C1.2.1.4 & Sub irrigation with geotextile & - & Unknown \\
\hline C1.2.1.5 & Sub irrigation with condensation & - & Unknown \\
\hline C1.2.1.6 & Aqua $4 D$ & 4 & Unknown \\
\hline C1.2.2 & Modifying the Farmers' crop plan $(C P)$ & 3 & Dominant Design \\
\hline C1.2.2.1 & Modifying the CP with economic subsides & 6 & Dominant Design \\
\hline C1.2.2.2 & Modifying the CP without economic subsides & 1 & Unknown \\
\hline C1.2.2.2 & Using $O G M$ & - & Unknown \\
\hline
\end{tabular}




\begin{tabular}{llll} 
C2 & Water resource production & & \\
$\mathrm{C} 2.1$ & Water treatments & 2 & \\
C2.1.1 & Wastewater recycling & 8 & Known \\
C2.1.2 & Desalinization (general suggestion) & 4 & Known \\
C2.1.2.1 & Thermic desalinization & - & Known \\
C2.1.2.2 & Reverse osmosis desalinization & - & Known \\
C2.1.2.3 & Electrodialysis desalinization & - & Unknown \\
C2.1.3 & Subsurface barriers & 1 & \\
C2.2 & Water collection & 2 & Known \\
C2.2.1 & Rainwater collection & 4 & Unknown \\
C2.2.2 & Water collection from the air humidity & 6 & \\
C2.3 & Water resource transport & & Known \\
C2.3.1 & From other Regions & 3 & Unknown \\
C2.3.2 & From other planets & 1 & \\
C2.4 & Artificial recharge of GW reservoirs & 9 & Unknown \\
C2.4.1 & Using infiltration wells & 3 & Unknown \\
C2.4.2 & Using infiltration trenches & 1 & Unknown \\
C2.4.3 & Using infiltration fields & 1 & \\
\hline
\end{tabular}

\section{Figure 4 approximately here}

Following the P-KCP description, the one-day generative workshop consisted of four main steps divided as follows:

1. The group discussed about the collective problem formulation starting form the different stakeholders' problem perspectives collected during the previous phase. This step focused on the definition of the GW overexploitation policy issue according to the different participants' backgrounds (Figure 5]).

2. A C-K theory expert briefly explained the $\mathrm{C}-\mathrm{K}$ theoretical framework and made a general illustration of the preliminary $\mathrm{C}$-tree $(1 \mathrm{~h} 30 \mathrm{~min})$. A detailed description of each policy alternative identified at the end of the P-K phase (i.e. dominant design) was carried out. The description of the C-tree branches was supported by the related K-space. At the end of this phase, each participant had to express preferences over the five most interesting/suitable policy alternatives for the given policy issue.

3. Small heterogeneous groups were formed to evaluate the dominant design of policy alternative and to propose innovative policy alternatives through the expansion of the $\mathbf{C}$-tree. Each group had to choose at least 5 policy alternatives/elements of the C-tree and to analyse the selected items in the following ways: carrying out a collective evaluation of the items providing specific and practical observations and criticisms, defining the interest of each chosen item using scale from 1 to 5 (not useful at all to very useful for the case study), providing suggestions and group recommendations for improving the analysed items, and prompting new policy alternatives or innovative combinations of them. Table 2 lists the elements of the C-tree selected from the groups for the second part of the generative workshop.

4. A general discussion concerning the results of the small group activities and the C-tree expansion suggestions. The general discussion leads to a portfolio of preferred policy alternatives shared with all the stakeholders and to the introduction of few innovative policy alternatives. 
5.3 The outputs of the C-phase generative workshop

During the generative workshop (Figure 6), the groups decided to work on specific policy alternatives. All three stakeholder groups considered "Water resource production - Artificial recharge of GW reservoirs" (C2.4) and "Shared management of GW aquifers" (C1.1.2.5) to be valuable alternatives. The "Drought early warning system" (C1.1.1.1.4.1) and "Water resource production - Wastewater recycling" (C2.1.1) alternatives were discussed at length. Perhaps the most interesting observation was the groups shifting focus from the alternatives generated via dominant design at the beginning of the workshop to the alternatives in the more innovative C-tree branches towards the last part of the workshop. The explored policy alternatives are shown in table 3

Table 3 Summary of the groups' activities

\begin{tabular}{lll}
\hline ID & Policy alternatives & Groups \\
\hline C1.1.2.5 & Shared management of GW aquifers & G1, G2, G3 \\
C2.4 & Artificial recharge of GW reservoirs & G1, G2, G3 \\
C1.1.1.1.4.1 & Drought early warning system & G1, G2 \\
C2.1.1 & Wastewater recycling & $\mathrm{G} 1, \mathrm{G} 2$ \\
C2.3.1 & Water transport from other Regions & $\mathrm{G} 1$ \\
C1.1.2.3.2 & Indirect controls of GW use & $\mathrm{G} 2$ \\
$\mathrm{C} 1.2 .2$ & Modifying the crop plan & $\mathrm{G} 2$ \\
$\mathrm{C} 1.1 .1 .2 .2$ & Indirect controls of SW use & $\mathrm{G} 3$ \\
$\mathrm{C} 1.1 .2 .3 .1 .4$ & GW aquifers monitoring & $\mathrm{G} 3$ \\
$\mathrm{C} 2.2 .1$ & Rainwater collection & $\mathrm{G} 3$ \\
\hline
\end{tabular}

\section{Figure 6]approximately here}

The workshop ended with the generation of a new set of policy alternatives: i) delocalization of the tomato production as new option for modifying the crop plan with economic subsidies (C-tree branch C.1.2.2), ii) sales at the end of irrigation season for the SW managed by the IC, i.e. a lower price for additional water volume in case of abundance (C-tree branch C1.1.1.1), iii) construction of new dams and related infrastructures at different scales. Furthermore, during the discussion, participants highlighted the need to combine policy alternatives in order to build a portfolio of actions. Specifically:

- The alternative "Water resource production - Artificial recharge of GW reservoirs" (C2.4) was proposed for increasing the water availability, considering GW aquifers as reservoirs for properly treated water. This alternative defined a new role/attribute for the GW reservoirs. The participants underlined the need to analyse the interdependencies between the alternative $\mathrm{C} 2.4$ and economic and management issues (e.g. the high costs of investment, the need for a detailed analysis of the aquifers state, the farmers' will to accept). During the discussion G1 suggested that the strength of this alternative was related to the abundance of winter water flow that could be collected and reintroduced by helping the aquifer hydrologic balance in dry and summer seasons (i.e. requiring newly built storage space). Participants were inspired by the alternatives explored in the related $\mathrm{C}$-tree branch and suggested implementing a decision support system to evaluate the economic and technical feasibility of the proposed sub-alternatives (C2.4.1, C2.4.2, C2.4.3) through detailed hydrological studies and analysis of current regulations. 
- The alternative "Shared management of GW aquifers" (C1.1.2.5) has been recognised a promising long term policy strategy, enhancing the innovative management of GW through shared and informed decision processes. The starting point has been a specific element of the K-space brought by one stakeholder on common pool resources management, according to Ostrom (1990)'s works introduced the awareness of the attributes defining the GW resource (i.e. the K-space expansion). Thus, GW is a shared resource characterized by a highly distributed structure with several collection points (i.e. wells) in private properties. In this regard, farmers tend to deny the legitimacy of a centralized entity for its management. Furthermore, stakeholders' knowledge clarified that the centralised "command and control" approach fails in verifying the actual number of wells and GW volume consumptions due to high management costs. In this context, a shared GW governance could empower the farmer community through reward regulations for virtuous GW use. Shared GW governance is supported by non-centralized self-organizing management structures (i.e. groups of farmers managing shared sub-aquifers). Following the discovered GW attributes the discussion leads to considering a distributed management system, in order to overcome the shortfalls of a centralized management for GW. At the end of the discussion, the principles of shared governance were revised by a few stakeholders and a new alternative was proposed: the IC as an integrated water resource management authority (i.e. SW and GW) through a specific GW withdrawals legislation, legitimated by a bottom-up participative decisional process in order to preserve the equal water distribution principle. For the shared management policy alternative, participants identified the necessity of: i) a detailed database on the quali-quantitative state of the aquifers from a physical point of view; ii) farmers' crop plan patterns from a management point of view in order to organize farms in sub-structures; iii) a learning process via pilot a case study from the social point of view.

- The alternative "Drought early warning system (DEWS)" (C1.1.1.1.4.1) was discussed with a twofold perspective. On the one hand, all the participants recognised that a DEWS does not have a direct effect on GW availability, underlining (i.e. via a specific element of the K-space related to innovation) the differences between superficial drought and GW shortage, the latter becoming visible with a significant delay. On the other hand, some participants observed that a DEWS managed outside the IC structure, could erase the farmers' dependency on the IC information system, encouraging irrigated crop practices in case of water abundance with a major negative impact of the GW aquifers. However, the experts of the G1 highlighted that analysis based on historical data could be beneficial for supporting the annual farmer's crop planning phase through timely information on water availability.

- The "Water resource production - Wastewater recycling" (C2.1.1) was considered a pragmatical alternative despite several technical reports showing that it does not significantly increase the quantity of available water. New elements were added to the K-space during the discussion (i.e. the IC is developing a project for introducing recycled wastewater in its distribution system). The discussion focused on the role of the IC as a management authority for an integrated water distribution system. The participants identified the following actions to be considered in a portfolio of policy alternatives: i) to explore innovative water treatment technologies in order to expand the related $\mathrm{C}$-tree branch; ii) to develop a reliable treatment process in order to recognize the different responsibilities in the production and distribution phases; iii) to face problems related to the recycled water quality, avoiding a decrease in crops conditions; iv) to fairly divide the energetic con- 
sumption of the treatment plant (i.e. paid by the Farmers or by the whole community); v) to develop strategies and infrastructures (i.e. water storage systems) in order to secure the water distribution in case of breakdown.

- The known alternatives "Indirect controls of GW use" (C1.1.2.3.2) and "Indirect controls of SW use" (C1.1.1.2.2) were considered as basic actions for the implementation of the more innovative policy alternatives. Providing more detailed information about the current situation would improve policy effectiveness. A key step would be the introduction of new institutional actors that could support the phase of gathering the above-mentioned information. Expansion of the two C-tree branches involves: i) controls on the energetic consumption via the collaboration with the energy company; ii) controls on the actual cultivated hectares and crop plans; iii) introduction or re-organization of a dedicated institutional actor for the data set task. Furthermore, G3 suggested a combination of policy alternatives, including the declaration of the annual crop plan as fundamental constraint for the access to the SW distribution system. Similarly, "GW aquifers monitoring" (C1.1.2.3.1.4) was recognized a basic action for the implementation of other policy alternatives.

- The "Water resource production - Water transport from other Regions" was considered a well established alternative with several related technical and organizational issues. Several Regions neighbouring the Apuglia Region have a surplus of SW and this additional water volume is already used for the urban potable water distribution system. The participants underpinned that there is available knowledge on the topic but that this alternative has not been explored yet for the agricultural system due to political issues concerning specific institutional actors that were not involved in the process. Consequentially, the missing knowledge did not allow to expand the C-tree branch.

- Within a generic perspective, the G2 suggested to explore the C-tree branch related to the alternative "Modifying the crop plan" (C.1.2.2). The economic subsidies driving the farmers' tendency to prefer irrigation practices were proposed, i.e. an economic compensation for voluntary GW quantity monitoring and reduction of GW consumption. Participants suggested that this branch should be explored in detail thanks to the combination with a related K-space expansion (i.e. missing knowledge on the subject).

- Lastly, the alternative "Water resource production - Rainwater collection" (C.2.2.1) was pictured as an essential, even if limited, answer to the GW overexploitation problem. The collected rainfall represents a small volume, but this alternative combined with other options of water resources production (i.e. "Wastewater recycling") could reduce the GW dependency of the agricultural sector. During the discussion a new alternative was generated and the group proposed to use rainwater and recycled wastewater for softening the seawater intrusion, increasing the GW quality. The rainfall collection practices were well known by the participants and they did not explore any discussion on the technical aspects.

It is worth underlining that the alternative "Water resource production - Water transport from other planets" (C.2.3.2.) represents a typical sample of innovative design through provocation. Thus, thanks to a successful generative phase where the $\mathrm{C}$-space was explored without any constraints, participants proposed an alternative for increasing the quantity of available water, considering the presence of natural resources on other planets. The discussion during the one-day generative workshop pointed out the lack of knowledge on technologies for universe exploration. 


\subsection{Evaluation of the Policy-KCP tool}

At the end of the process, a questionnaire on the advantages and disadvantages of the P-KCP participatory tool was distributed to all the participants, followed by detailed interviews. Participants have been asked to reply to open evaluation questions, namely, “Overall, what did you like about the P-KCP? Could you please describe strengths and weaknesses of the process proposed for the innovative design of policy alternatives?" The participants' answers helped the evaluation of the process for future improvement. Specifically, within the pilot case study, the methodology received positive feedback, e.g. "good the C-tree building activity", "open discussions", "useful the information exchange before the discussions and C-tree", "different points of view considered". The involved stakeholders considered the P-KCP an innovative and intriguing methodological approach since during the final discussion further innovative policy alternatives emerged (see section 5.3. The highlighted advantages include the pre-workshop activities for eliciting and aligning the available knowledge on the policy problem under consideration (i.e. D- and K-phase). Furthermore, the K-phase and the preliminary C-tree were considered useful for structuring the discussion during the one-day generative workshop, without influencing the stakeholders' opinion because it was mirroring their own point of view and partial K-spaces. Stakeholders appreciated the supplied information about the policy problem, with specific emphasis to the knowledge sharing sessions (i.e. K-sessions) and the definition of a shared problem understanding. They recognized that the P-KCP approach brought them at the same level during the discussions, in a more inclusive participatory perspective.

On the other side, the pinpointed disadvantages were mainly concerned the K-space building time-consuming activity and the one-day workshop timeline. The majority of participants complained about the lack of time for continuing exploring the C-tree and for further discussions. Specifically, the experts considered the K-sessions long despite their recognition that the lack of stakeholders' availability was an important driver for the workshop organization decisions. Furthermore, one of the experts stated the need for a longer training on C$\mathrm{K}$ theory, in order to deeply understand the generative process. Lastly, few participants underlined the missing validation for the terminology used in the C-space.

\section{Discussion}

From a methodological point of view, the C-K theory framework and the P-KCP participatory tool offers a formal support for policy design, assisting the generation of innovative policy alternatives. In the presented policy design process based on $\mathrm{C}-\mathrm{K}$ theory, it was possible to observe and formalize a "generative mechanism" aimed at modifying the stakeholders' values structure with the consequential expansion of the set of policy alternatives. It improved the quality of the participation process for the policy design and expanded its scope. This was achievable thanks to three main differences between the P-KCP participatory tool and other traditional participatory approaches (e.g. Creighton, 2005; Majone, 1993): i) the alignment of different stakeholders' knowledge independently from the source in order to build a collective problem understanding and a shared concern; ii) the assisted sharing of structured knowledge allowing the expansion of the available knowledge (i.e. K-space expansion) as a starting point for the unfixation process (i.e. C-space expansion); iii) the methodological support for innovation management applied to policy design. We discuss these briefly in the following. 
Firstly, the dichotomy between expert and local knowledge, characterizing the traditional participatory approaches, has been overcome thanks to the P-KCP participatory tool for the design of policy alternatives. Different knowledge subsets of the K-space have been aligned in a more inclusive participatory process. On one side, stakeholders are experts of the local policy issue and they offer a valuable insight for the problem formulation with a K-space expansion. On the other side, experts in several domains linked to the policy goal (e.g. technical, organizational, legislative expertise) facilitated the group learning process through the $\mathrm{K}$ - and $\mathrm{C}$-space co-evolution. P-KCP aims to equally use each stakeholder's knowledge, in order to support the group generative mechanism for the innovative design of policy alternatives, enhancing a common problem understanding and improving engagement and consensus on the whole policy making process. New information not considered before has now become available.

Secondly, P-KCP reestablishes communication between stakeholders by unfixing the group from the dominant design, i.e. traditional and known policy alternatives. Fixation phenomena within the policy design process bring policy makers and stakeholders in conflicting and unsustainable situations. As it is possible to observe from our pilot case study, at the beginning of the one-day generative workshop, participants tended to debate only about the dominant design, while at the end they were able to explore and expand more innovative branches of the $\mathrm{C}$ tree with mutual consent, on both traditional and non-traditional solutions. Thus, the first part of the workshop leaded antagonistic stakeholders to discuss on the collected knowledge and to agree with the different problem formulations presented, allying their differences (see section 5.1). Each participant realized the missing information and was more accommodating to new K-space expansions. This represented the starting point for stimulating discussions during the generative mechanism for the C-space exploration. Initially, the discussions were driven by conflicting situations due to knowledge limitations and fixation phenomena, while after the injection of new knowledge and the alignment of problem frames, they were more willing to cooperate in constructive debates. In addition, the injection of new knowledge related to non-traditional solutions (and provocations such as the alternative "Water resource production - Water transport from other planets") had positive effects on their collective activities and workshop results. Unfixed participants were available to propose new solutions or integrate known alternatives in a different perspective. Moreover, they were able to introduce useful knowledge K-space expansion) that became operational in the new alternative propositions $\mathbf{C}$-space expansion)(see section 3 .

Lastly, P-KCP and the C-K theory framework provides a support for the innovative generation of policy alternatives. Traditional participatory approaches focus their efforts on the problem identification and the collective evaluation of known alternatives, following the dominant design. Several structured approaches such as Problem Structuring Methods drive the identification of known alternatives and not of the ones that are unimaginable. The generation of innovative policy alternatives is not considered and managed explicitly. In order to allow the emergence of unimaginable alternatives, a formal methodology for innovation management is needed. Under such perspectives, $\mathrm{C}-\mathrm{K}$ theory and $\mathrm{P}-\mathrm{KCP}$ represent the required guidance for a wider and inclusive policy design process.

Discussing the differences between P-KCP and KCP, the first one to note is the peculiar context in which we operate. With reference to the main features defining public policy, discussed in De Marchi et al (2016), the KCP has been conceived and operationally validated in the private sector where innovation management is a central activity. Participants to KCP are generally incentivized to work together sharing the same company 
objectives and the only differences are between departments expertise and specific goals. Whereas, in public decision processes, the information is distributed, but not necessarily shared between different stakeholders with their own goals, backgrounds, expertise and knowledge bases. The lack of motivation to participate to the policy design process as well as of the willingness to change towards a more inclusive participatory approach are pivotal drivers of the policy making process.

Indeed, under a participatory decision making perspective, an effective policy design process requires the identification of a shared concern in order to motivate stakeholders' commitment. The P-KCP methodologically supports the participants for its identification. Generally antagonistic stakeholders are not motivated to work together, they have conflicting objectives, different values systems and distant personal perceptions of the same problem. Moreover, Kim and Mauborgne (1998) underlined that people tend to react more positively when treated with higher levels of "procedural justice". Ackermann and Heinzerling (2004) stated that the ability to capture, structure and analyse contributions from participants assists not only in ensuring that "procedural rationality" (Simon, 1976) takes place but also that "procedural justice" is served (Kim and Mauborgne, 1995), encouraging stakeholders to absorb a larger share of ownership for the outcomes, therefore increasing the likelihood of their implementation. A concept similar to the shared concern has been discussed in Ostanello and Tsoukiàs (1993), where the identification of the meta-object of the Interaction Space allows an integrated problem representation to be developed. In this regard, P-KCP builds a collective problem understanding allowing the stakeholders to motivate to participation. In case of stakeholders lacking proactive efforts and a shared concern, each stakeholder tends to think and discuss policy alternatives related only to their individual problem framing (i.e. fixation phenomenon). Building a collective problem formulation allows the activation of the design process while conflicting situations considering the individual perceptions causes clashes.

Secondly, in classical KCP participants are physically working in the same company, while stakeholders and institutional actors are often delocalised and have to interact from distance. The geographical constraint and the time limitation make the realization of the classical seminars for the K-space expansion difficult. During a KCP, each participant develops its own K-space and several seminars are developed in order to offer more knowledgeable guidance for the generative phase and the C-space evolution. Whereas, during a P-KCP process, the learning process within the K-phase is compressed because the K-space has been built by analysts. Stakeholders receive an initial set of alternatives and are required to discuss the starting point and explore it in order to support the C-space expansions. The design management team elicits and structures stakeholders' knowledge before the generative workshop due to the lack of engagement in the process and in the policy issues as well as the lack of skills in developing research activities in a systematic way. This represents an innovation in $\mathrm{C}-\mathrm{K}$ theory based tools.

\section{Conclusion}

This paper presents a pilot application of an original approach for the innovative design of policy alternatives. $\mathrm{P}-\mathrm{KCP}$ is a methodology formalizing the policy design process based on $\mathrm{C}-\mathrm{K}$ theory. It supports the generation of unimaginable alternatives thanks to the co-evolution of the $\mathrm{K}$ - and $\mathrm{C}$ - spaces according to the $\mathrm{C}$-K framework. It connects local and expert knowledge within the whole design process thanks to the construction of a collective problem understanding. 
Mainstream policy analysis does not focus on the generation of novel policy alternatives and it is more effective in relation to the evaluation of known alternatives. Thus, participatory processes have been designed to facilitate the exchange of knowledge in order to develop more or less shared process of evaluation. The identification of traditional policy alternative (dominant design) is an ordinary process thanks to several approaches derived for instance from Problem Structuring Methods. For this reason, we suggest the use of a generative participatory process separated from the evaluative one, using a $\mathbf{C}-\mathrm{K}$ theory based policy design tool.

The experiences carried out in the Apulia case study supported the application of the P-KCP participatory tool for the design of policy alternatives. It creates new insights and evidence. It brings together stakeholders, experts, institutional and non-institutional actors aiding them to find new ways of working together efficiently, generating innovative possible alternatives and encouraging longer term thinking.

P-KCP facilitates the transfer of knowledge, enabling participants to embed learning back into their organisations. As a result, we observe that policy design is a generative process for the creation of a new dimension of values, overtaking fixation phenomena through the creation of new variables and/or the elimination of variables without value for the process. For example, within the case study, we were able to introduce new alternatives in order to modify the value structures in a successful policy making process (i.e. from the dominant design alternatives such as the pricing strategy, to the innovative ones as the shared management of GW aquifers).

In conclusion, this work considers that the traditional participatory methodologies focus on how different stakeholders with different preferences and decisional criteria are going to decide together once design of alternatives is given. $\mathrm{C}-\mathrm{K}$ theory, instead, offers a theoretical framework for an advanced participatory policy design process. Specifically, the P-KCP participatory tool, assists policy makers and stakeholders to work together for the generation of alternatives overcoming difficulties of the traditional approaches. The knowledge alignment represents the starting point for building a shared concern and breaking the fixation phenomena, toward a generative phase to go beyond known solutions.

We acknowledge our findings have some limitations, suggesting pathways for improvement. Firstly, the pilot case study offered several insights for improving the applied methodology and assuring its replicability. The positive results we obtained require further inquiry from different disciplines perspective, such as policy science. Secondly, a open challenge for the future is to demonstrate, thanks to a portfolio of case studies, that P-KCP can be used with any type of policy making process. Thirdly, for managing the P-KCP participatory tool, it is necessary to possess a theoretical understanding of the $\mathrm{C}$-K framework: both the expertise, on the policy issue and on the process, are equally valuable for the success of the participatory activity. Fourthly, stakeholders engagement activities, the identification of the gatekeeper-stakeholder and the K-space building process have been time demanding, and further research is essential. Lastly, the issue of the policy design legitimacy has not been investigated in this paper and in general in participatory public decision making processes; a notable exception is Mazri (2007). The topic will be discussed and refined in a further development of this work. 


\section{Acknowledgement}

The research activity described in this work have been financially supported by the INNDOPP (Innovative Design of Public Policies) project, funded by PSL Research University. It has been developed in cooperation with the National Research Council - Water Research Institute (CNR -IRSA) of Bari (Italy) and the Centre de Gestion Scientifique of the Ecole des Mines ParisTech, Paris (France). We would like to thank the institutional and non-institutional stakeholders that provided their knowledge and expertise at the base of this work. Moreover, a great thanks goes to the Capitanata Irrigation Consortium (Consorzio di Bonifica di Capitanata) and to Dr. Luigi Nardella for their general support, engagement and availability during the work sessions.

\section{References}

Ackermann F, Eden C (2011) Strategic Management of Stakeholders: Theory and Practice. Long Range Planning 44(3):179-196, DOI 10.1016/j.lrp.2010.08.001

Ackermann F, Heinzerling L (2004) Priceless: On Knowing the Price of Everything and the Value of Nothing. The New Press, New York, NY, DOI 10.1136/bmj.330.7499.1091

Adla A, Zarate P, Soubie J (2011) A Proposal of Toolkit for GDSS Facilitators. Group Decision and Negotiation 20(1):57-77, DOI 10.1007/s10726-010-9204-8

Agogué M, Kazakçi AO (2014) 10 Years of C-K Theory: A Survey on the Academic and Industrial Impacts of a Design Theory. An Anthology of Theories and Models of Design pp 219-235, DOI 10.1007/ 978-1-4471-6338-1_11

Agogué M, Hooge S, Arnoux F, Brown I (2014) An Introduction to Innovative Design. Elements and Applications of C-K Theory. TRANSVALOR, Paris

Alexander C (1964) Notes on the Synthesis of Form. Harvard University Press, Cambridge, MA, USA

Alexander ER (1982) Design in the Decision-Making Process. Policy Sciences 14:279-292

Alford J (2009) Engaging Public Sector Clients: From Service Delivery to Co-Production. Palgrave MacMillan, Houndmills, UK

Alshuwaikhat HM, Nkwenti DI (2002) Visualizing decisionmaking: Perspectives on collaborative and participative approach to sustainable urban planning and management. Environment and Planning B: Planning and Design 29(4):513-531, DOI 10.1068/b12818

Ananda J, Herath G (2003) Incorporating stakeholder values into regional forest planning: a value function approach. Ecological Economics 45(1):75-90

Archer LB (1963) Systematic method for designers. In: Developments in Design Methodology, John Wiley Sons, Chirchester

Archer LB (1970) An overview of the structure of the design process. In: G Moore (Ed) (ed) Emerging methods in environmental design and planning, MIT, Cambridge, MA, USA, pp 285-307

Bardach E (1977) The implementation game. University of Chicago press, Chicago

Bayazit N (2004) Investigating design: A review of forty years of design research. Design Issues 20(1):16-29

Bayley C, French S (2008) Designing a participatory process for stakeholder involvement in a societal decision. Group Decision and Negotiation 17(3):195-210, DOI 10.1007/s10726-007-9076-8 
Beierle TC (2002) The quality of stakeholder-based decisions. Risk Analysis 22(4):739-749, DOI 10.1111/ 0272-4332.00065

Beierle TC, Cayford J (2002) Democracy in practice: Public participation in environmental decisions. Resources for the Future, Washington DC

Bemelmans-Videc M, Vedung E (1998) Conclusion: Policy Instrument Types, Packages, Choices and Evaluation. In: Bemelmans-Videc M, Rist RC, Vedung E (eds) Carrots, Sticks and Sermons: Policy Instruments and Their Evaluation, Transaction Publishers, New Brunswick, pp 249-273

Bobrow D (2006) Policy Design: Ubiquitous, Necessary and Difficult. In: B Guy Peters and Jon Pierre (ed) Handbook of public policy, Sage Publications, London, United Kingdom, pp 75 - 96

Bobrow D, Dryzek JS (1987) Policy Analysis by Design. University of Pittsburgh Press, Pittsburgh

Bressers H, Klok P (1988) Fundamentals for a theory of policy instruments. International Journal of Social Economics 15(3/4):22-41

Brown T (2008) Design Thinking. Harvard Business Review 84(6):15-24

Brown T (2009) Change by Design: How Design Thinking Transforms Organisation and Inspires Innovation. Harper Collins, New York, NY

Brugha R, Varvasovsky Z (2000) Stakeholder analysis: a review. Health Policy and Planning 15:239-246

Buchanan R (1992) Wicked Problems in Design Thinking. Design Issues 8(2):5-21

Celino A, Concilio G (2011) Explorative Nature of Negotiation in Participatory Decision Making for Sustainability. Group Decision and Negotiation 20(2):255-270, DOI 10.1007/s10726-010-9197-3

Checkland P (2000) Soft systems methodology: a thirty year retrospective. Systems Research and Behavioral Science 17:S11-S58

Colorni A, Tsoukiàs A (2018) What is a Decision Problem ? Designing Alternatives. In: Matsatsinis N, Grigoroudis E (eds) Preference Disaggregation in Multiple Criteria Decision Analysis, Springer International Publishing, Switzerland, pp 1-15, DOI 10.1007/978-3-319-90599-0_1

Creighton JL (2005) The Public participation Handbook. Jossey-Bass, NY, USA

Daniell KA, Mazri C, Tsoukiàs A (2010) Real world decision-aiding: a case of participatory water management. In: Insua DR, French S (eds) e-Democracy: A Group Decision and Negotiation Perspective, vol 5, Springer, pp $125-150$

De Marchi G, Lucertini G, Tsoukiàs A (2016) From evidence-based policy making to policy analytics. Annals of Operations Research 236(1):15-38, DOI 10.1007/s10479-014-1578-6

Del Rıo P, Carrillo-Hermosilla J, Konnola T (2010) Policy strategies to promote eco-innovation. Journal of Industrial Ecology 14(4):541-557

Dorst K, Cross N (2001) Creativity in the Design Process: Co-Evolution of Problem Solution. Design Studies 22(5):425-437

Eden C, Ackermann F (2004) Cognitive mapping expert views for policy analysis in the public sector. European Journal of Operational Research 152(3):615-630, DOI 10.1016/S0377-2217(03)00061-4

Eden C, Ackermann F (2013) Problem structuring: on the nature of, and reaching agreement about, goals. EURO Journal on Decision Processes 1(1):7-28

Elmore RF (1987) Instruments and strategy in public policy. Policy Studies Review 7(1):174-186 
Elmquist M, Segrestin B (2009) Sustainable development through innovative design: lessons from the KCP method experimented with an automotive firm. Int J Automotive Technology and Management 9(2):229-244

Ferretti V, Pluchinotta I, Tsoukiàs A (2019) Studying the generation of alternatives in public policy making processes. European Journal of Operational Research 273:353-363

Fischer F (2000) Citizens, experts and the environment: The politics of local knowledge. Duke University Press, Durham

Fischer F, Miller G, Sidney MS (2007) Handbook of public policy: theory, politics, and methods. SAGE Publications Ltd., London, United Kingdom, DOI 10.4135/9781848608054

Forester J (1999) The Deliberative Practitioner: Encouraging Participatory Planning Processes. MIT Press, Cambridge MA

Freeman RE (2010) Strategic Management: A Stakeholder Approach. Cambridge University Press, Cambridge, MA, USA

French S, Bayley C (2011) Public participation : comparing approaches. Journal of Risk Research 14(2):37-41, DOI 10.1080/13669877.2010.515316

French S, Insua DR, Ruggeri F (2007) E-participation and decision analysis. Decision Analysis 4:1-16

Friend J, Hickling A (1987) Planning under pressure. The strategic choice approach. Pergamon, Oxford, United Kingdom

Friend J, Power J, Yewlett C (1974) Public Planning: The Inter-Corporate Dimension. Tavistock, London, United Kingdom

Giordano R, D’Agostino D, Apollonio C, Lamaddalena N, Vurro M (2013) Bayesian Belief Network to support conflict analysis for groundwater protection: The case of the Apulia region. Journal of Environmental Management 115:136-146, DOI 10.1016/j.jenvman.2012.11.011

Giordano R, D’Agostino D, Apollonio C, Scardigno A, Pagano A, Portoghese I, Lamaddalena N, Piccinni AF, Vurro M (2015) Evaluating acceptability of groundwater protection measures under different agricultural policies. Agricultural Water Management 147:54-66, DOI 10.1016/j.agwat.2014.07.023

Giordano R, Brugnach M, Pluchinotta I (2017a) Ambiguity in Problem Framing as a Barrier to Collective Actions: Some Hints from Groundwater Protection Policy in the Apulia Region. Group Decision and Negotiation 26(5):911-932, DOI 10.1007/s10726-016-9519-1

Giordano R, Pagano A, Pluchinotta I, Olivo R, Hernandez SM, Lafuente ES (2017b) The complexity of the network of interactions in flood emergency management : The Lorca flash flood case. Environmental Modelling and Software 95:180-195, DOI 10.1016/j.envsoft.2017.06.026

Gregory R, Fischhoff B, McDaniels T (2005) Acceptable input: Using decision analysis to guide public policy deliberations. Decision Analysis 2:4-16

Gunningham N, Grabosky P, Sinclair D (1998) Smart regulation: Designing environmental policy. Clarendon Press, Oxford

Hand LC (2012) Public Policy Design and Assumptions about Human Behaviour. In: Western Political Science Association's Annual Conference

Harrison S, Qureshi M (2000) Choice of stakeholder groups and members in multicriteria decision models. Nat Resour Forum 24(1):11-19 
Hatchuel A, Weil B (1999) Pour une théorie unifiée de la conception, Axiomatiques et processus collectifs. CGS Ecole des Mines, GIS cognition-CNRS

Hatchuel A, Weil B (2002) C-K theory: Notions and applications of a unified design theory. Proceedings of the Herbert Simon International Conference on « Design Sciences » pp 1-22

Hatchuel A, Weil B (2003) a New Approach of Innovative Design : an Introduction To C-K Theory. International Conference on Engineering Design (January 2003):1-15, DOI citeulike-article-id:4891368

Hatchuel A, Weil B (2009) C-K design theory: An advanced formulation. Research in Engineering Design 19(4):181-192

Hatchuel A, Le Masson P, Weil B (2004) C-K Theory in Practice : Lessons From Industrial Applications. Design Conference 2004 pp 245-258

Hatchuel A, Le Masson P, Weil B (2008) Teaching innovative design reasoning: How could C-K theory help? Proceedings of 10th International Conference on Engineering and Product Design Education pp 73-78

Hatchuel A, Le Masson P, Weil B, Agogué M, Kazakçi AO, Hooge S (2015) Multiple forms of applications and impacts of a design theory -ten years of industrial applications of C-K theory. In: Lindemann ACeU (ed) Impact of Design Research on Industrial Practice - Tools, technology, and Training, December, Springer, Munich, pp 189-209

Hood C (1986) The tools of government. Chatham House Publishers, Chatham

Hooge S, Béjean M, Arnoux F (2016) Organising for Radical Innovation: the Benefits of the Interplay Between Cognitive and Organisational Processes in Kcp Workshops. International Journal of Innovation Management 20(4):1-33, DOI 10.1142/S1363919616400041

Howlett M (2004) Beyond good and evil in policy implementation: Instrument mixes, implementation styles and second generation theories of policy instrument choice. Policy \& Society 23(2):1-17

Howlett M (2011a) Designing Public Policies: Principles and Instruments. Routledge Textbooks in Policy Studies, London

Howlett M (2011b) Revisiting Policy Design: The Rise and Fall (and Rebirth?) of Policy Design Studies. In: General Conference of the European Consortium for Political Research (ECPR), pp 1-32

Howlett M (2014) From the 'old' to the 'new' policy design: Design thinking beyond markets and collaborative governance. Policy Sciences 47(3):187-207, DOI 10.1007/s11077-014-9199-0

Howlett M, Lejano R (2013) Tales from the crypt: The rise and fall (and re-birth?) of policy design studies. Administration \& Society 45(3):356-380

Howlett M, Mukherjee I, Woo JJ (2015) From tools to toolkits in policy design studies: the new design orientation towards policy formulation research. Policy and politics 43(2):291-311

Hysing E (2009) From government to governance? A comparison of environmental governing in Swedish forestry and transport. Governance 22:547-672

Kazakçi AO, Tsoukiàs A (2005) Extending the C-K design theory: A theoretical background for personal design assistants. Journal of Engineering Design 16(4):399-411

Keyes JM (1996) Power Tools: The Form and Function of Legal Instruments for Government Action. Canadian Journal of Administrative Law and Practice 10:133-174 
Kim WC, Mauborgne RA (1995) A Procedural Justice Model of Strategic Decision-Making: Strategy Content Implications in the Multinational. Organization Science 6(1):44-61, DOI 10.1287/orsc.6.1.44

Kim WC, Mauborgne RA (1998) Procedural Justice, Strategic Decision Making, and the Knowledge Economy. Strategic Management Journal 19(4):323-338

Lasswell H (1954) Key Symbols, Signs and Icons. In: L Bryson, L Finkelstein, R M MacIver, (Eds) RM (eds) Symbols and Values: An Initial Study, Harper \& Bros, New York, pp 77-94

Lasswell H (1956) The decision process: Seven categories of functional analysis. Bureau of Governmental Research,College of Business and Public Administration, University of Maryland.

Lasswell H (1971) A Pre-view of Policy Sciences. American Elsevier, New York

Lavin J (2010) Participatory Processes and Instruments. In: Rios Insua D, French S (eds) E-participation. A group decision and negotiation perspective, Springer Netherlands, Dordrecht

Le Masson P, Weil B, Hatchuel A (2014) Théorie, méthodes et organisations de la conception. TRANSVALOR, Paris

Levi-Faur D (2012) The Oxford Handbook of Governance. Oxford University Press, Oxford, UK

Liedtka J, King A, Bennett K (2013) Solving Problems with Design Thinking: Ten Stores of What Works. Columbia University Press, New York, NY

Lienert J, Schnetzer F, Ingold K (2013) Stakeholder analysis combined with social network analysis provides finegrained insights into water infrastructure planning processes. Journal of Environmental Management 125:134148, DOI 10.1016/j.jenvman.2013.03.052

Linder SH, Peters BG (1984) From social theory to policy design. Journal of Public Policy 4(3):237-259, DOI $10.1017 / \mathrm{S} 0143814 \mathrm{X} 0000221 \mathrm{X}$

Lowi T (1985) The State in Politics: The Relation Between Policy and Administration. In: Noll R (ed) Regulatory Policy and the Social Sciences, University of California Press, Berkeley, pp 67-105

Lynn LE, Gould SG (1980) Designing Public Policy: A Casebook on the Role of Policy Analysis. Goodyear Publishing Company, Santa Monica, CA

Majone G (1993) Pitfalls of analysis. In: Majone G, Quade E (eds) International series on applied system analysis, John Wiley \& Sons Ltd., New York, pp 7-22

Martin R (2009) The Design of Businesses: Why Design Thinking is the Next Competitive Advantage. Harvard Business Press, Boston, MA

Marttunen M, Mustajoki J, Dufva M, Karjalainen T (2013) How to design and realize participation of stakeholders in MCDA processes ? A framework for selecting an appropriate approach. EURO J Decis Process 3(1-2):187214, DOI 10.1007/s40070-013-0016-3

May PJ (1981) Hints for Crafting Alternative Policies. Policy Analysis 7(2):227-244

May PJ (1991) Reconsidering Policy Design: Policies and Publics. Journal of Public Policy 11(02):187, DOI 10.1017/S0143814X0000619X

May PJ (2003) Policy Design and Implementation. In: Guy Peters B, Pierre J (eds) Handbook of Public Administration, Sage Publications, Beverly Hills, pp 223-233

Mayntz R (1979) Public bureaucracies and policy implementation. International Social Science Journa 31(4):633645 
Mayntz R (1981) The Changing Conditions of Effective Public Policy: A New Challenge for Policy Analysis II(2):123-143

Mazri C (2007) Apport méthodologique pour la structuration de processus de décision publique en contexte participatif. Le cas des risques industriels majeurs en France. Université Paris-Dauphine, Paris

Mintrom M, Luetjens J (2016) Design Thinking in Policy making Processes: Opportunities and Challenges. Australian Journal of Public Administration 75(3):391-402, DOI 10.1111/1467-8500.12211

Moore MH (1995) Creating Public Value: Strategic Management in Government. Harvard University Press, Cambridge, MA, USA

Nogueira F, Borges M, Wolf JH (2017) Collaborative Decision-Making in Non-formal Planning Settings. Group Decision and Negotiation 26(5):875-890, DOI 10.1007/s10726-016-9518-2

Norese M, Rolando D, Fregonara E (2015) Integration of Problem Structuring Methods: A Methodological Proposal for Complex Regional Decision-Making Processes. International Journal of Decision Support System Technology 7(2):58-83, DOI 10.4018/IJDSST.2015040104

Oppl S (2017) Supporting the Collaborative Construction of a Shared Understanding About Work with a Guided Conceptual Modeling Technique, vol 26. Springer Netherlands, DOI 10.1007/s10726-016-9485-7

Ostanello A, Tsoukiàs A (1993) An explicative model of 'public' interorganizational interactions. European Journal of Operational Research 70:67-82

Ostrom E (1990) Governing the Commons: The Evolution of Institutions for Collective Action. Cambridge Univ. Press, Cambridge, U. K.

Ostrom E (2010) Governing a Commons from a Citizen's Perspective. Heinrich-Boell Stiftung pp 1-9

O’Toole L (2000) Research on Policy Implementation: Assessment and Prospects. Journal of Public Administration Research and Theory 10(2):263-288

Pahl G, Beitz W (1984) Engineering design, a systematic approach. The Design Council, London

Peters BG, Pierre J (1998) Governance Without Government? Rethinking Public Administration. Journal of Public Administration Research and Theory 8(2):223-244

Pidd M (2004) Complementarity in systems modelling. In: Michael Pidd (ed) Systems modelling: theory and practice Theory and Practice, Chichester, Chichester, England, pp 1-20

Pluchinotta I (2015) Multi-Agent Modelling For Distributed Intelligent Decision In Water Management. Doctoral thesis in Computer Science (LAMSADE-CNRS, Université Paris Dauphine, PSL Univ, France) and in Civil and Enviromental Engegneering (Techinical University of Bari, Ital

Pluchinotta I, Pagano A, Giordano R, Tsoukiàs A (2018) A system dynamics model for supporting decisionmakers in irrigation water management. Journal of Environmental Management 223:815-824, DOI 10.1016/j. jenvman.2018.06.083

Pollock S, Rothkopf M, Barnett A (1994) Operational Research and the Public Sector. North Holland, Amsterdam

Portoghese I, D’Agostino D, Giordano R, Scardigno A, Apollonio C, Vurro M (2013) An integrated modelling tool to evaluate the acceptability of irrigation constraint measures for groundwater protection. Environmental Modelling \& Software 46:90-103

Reed M, Graves A, Dandy N, Posthumus H, Hubacek K, Morris J, Prell C, Quinn CH, Stringer LC (2009) Who's in and why? A typology of stakeholder analysis methods for natural resource management. Journal of Environ- 
mental Management 90(5):1933-1949, DOI 10.1016/j.jenvman.2009.01.001

Renn O (2006) Participatory processes for designing environmental policies. Land Use Policy 23(1):34-43, DOI 10.1016/j.landusepol.2004.08.005

Rittel H, Webber M (1973) Dilemmas in a general theory of planning. Policy Sciences

Rosenhead J (2006) Past, present and future of problem structuring methods. Journal of the Operational Research Society 57(7):759-765, DOI 10.1057/palgrave.jors.2602206

Rowe GT, Horlick-Jones JW, Pidgeon N (2005) Difficulties in evaluating public engagement initiatives: Reflections on an evaluation of the UK GM Nation? Public debate. Public Understanding or Science 14:331-352

Rowe P (1998) Design Thinking. MIT Pres, Cambridge, MA

Sabatier P (2007) Theories of the policy process. Westview Press, Boulder

Salamon L (1981) Rethinking Public Management: Third Party Government and the Changing Forms of Government Action. Public Policy 29(3):255-275

Santoro S, Pluchinotta I, Pagano A, Pengal P, Cokan B, Giordano R (2019) Assessing stakeholders' risk perception to promote Nature Based Solutions as flood protection strategies: The case of the Glinščica river (Slovenia). Science of the Total Environment 655:188-201, DOI 10.1016/j.scitotenv.2018.11.116

Schneider A, Ingram H (1997) Policy Design for Democracy. University of Kansas Press, Lawrence

Schon D (1983) The reflective practitioner: How professionals think in action. Basic Books (Reprinted 1995), New York

Sharif Ullah AMM, Rashid MM, Tamaki J (2012) On some unique features of C-K theory of design. CIRP Journal of Manufacturing Science and Technology 5(1):55-66, DOI 10.1016/j.cirpj.2011.09.001

Simon HA (1954) Some strategic considerations in the construction of social science models. In: Simon H (ed) Models of Bounded Rationality: Behavioural Economics and Business Organization, MIT Press, Cambridge, MA, USA

Simon HA (1969) The sciences of the artificial. MIT Press, Cambridge, MA

Simon HA (1976) From substantive to procedural rationality. In: Latsis S (ed) Method and Appraisal in Economics, Cambridge University Press, Cambridge, UK

Sterman JD (2000) Business dynamics: Systems thinking and modeling for a complex world. Boston, DOI 10. 1057/palgrave.jors. 2601336

Sterner T (2003) Policy Instruments for Environmental and Natural Resource Management. Resource for the Future Press, Washington DC

Suh N (1990) Principles of design. Oxford University Press, New York

Tavella E, Franco LA (2015) Dynamics of Group Knowledge Production in Facilitated Modelling Workshops: An Exploratory Study. Group Decision and Negotiation 24(3):451-475, DOI 10.1007/s10726-014-9398-2

Tsoukiàs A (2007) On the concept of decision aiding process: An operational perspective. Annals of Operations Research 154(1):3-27, DOI 10.1007/s10479-007-0187-z

Tsoukiàs A, Montibeller G, Lucertini G, Belton V (2013) Policy analytics: an agenda for research and practice. EURO Journal on Decision Processes 1(1-2):115-134, DOI http://dx.doi.org/10.1007/s40070-013-0008-3

UNDP UNDP (2012) Multi-Stakeholder Decision-Making A Guidebook for Establishing a Multi-Stakeholder Decision-Making Process to Support Green, Low-Emission and Climate-Resilient Development Strategies 
Utterback J, Abernathy W (1975) A Dynamic Model of Process and Product Innovation. Omega, The Int J1 of Mgmt Sci 3(6):639-665

Vennix JAM (1996) Group model-building: tackling messy Problems. System Dynamics Review 15(4):379-401

Webler T, Renn O (1995) A Brief Primer on Participation: Philosophy and Practice. In: Renn O, Webler T, Wiedemann P (eds) Fairness and Competence in Citizen Participation Evaluating Models for Environmental Discourse, Springer, pp 17-33

Weimer D (1992) The Craft of Policy Design: Can It Be More Than Art? Review of Policy Research 11(3-4):370388, DOI 10.1111/j.1541-1338.1992.tb00479.x

Wildavsky A (1979) Speaking Truth to Power: The Art and Craft of Policy Analysis. Little-Brown, Boston

Wilensky R (1981) Meta-Planning: Representing and Using Knowledge About Planning in Problem Solving and Natural Language Understanding. Cognitive Science 5:197-233, DOI 10.1016/B978-1-4832-1446-7.50044-3

Woodside K (1986) Policy Instruments and the Study of Public Policy. Canadian Journal of Political Science 19(4):775-793, DOI 10.1017/S0008423900055141

Zarate P (2013) Tools for Collaborative Decision-Making. London, United Kingdom, DOI 10.1002/ 9781118574690 


\section{Policy Design}

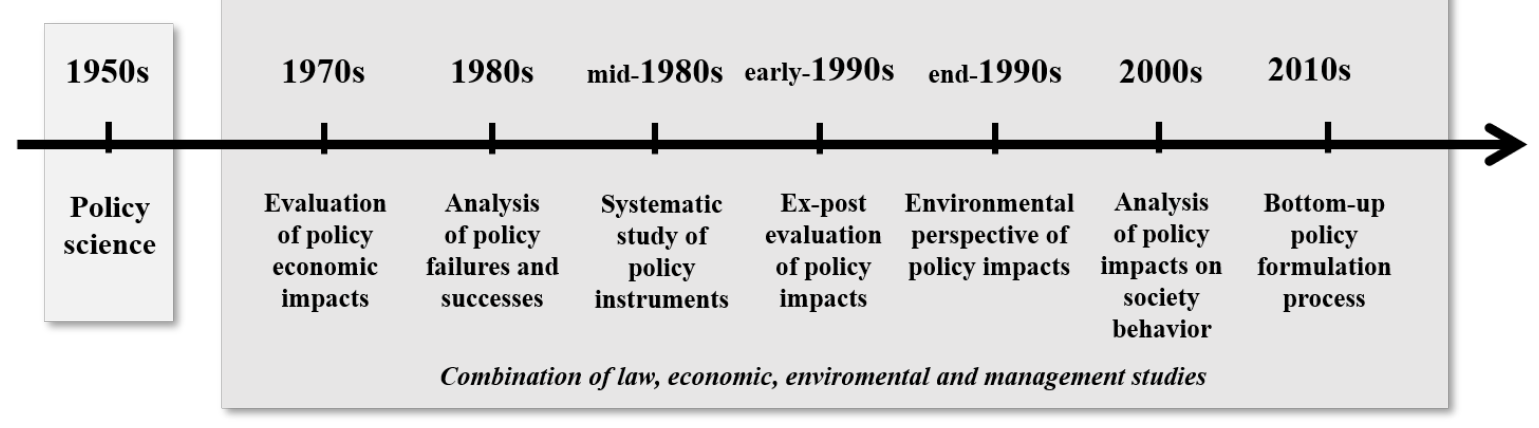

Fig. 1 Timeline showing the evolution of policy design literature 


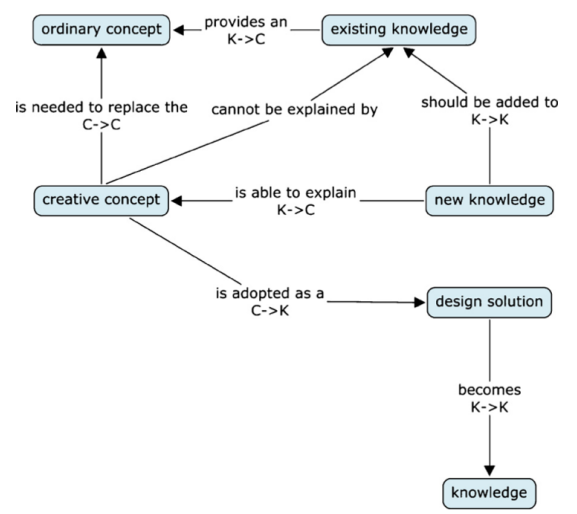

Fig. 2 A schematic illustration of C-K theory operators (Sharif Ullah et al 2012) 


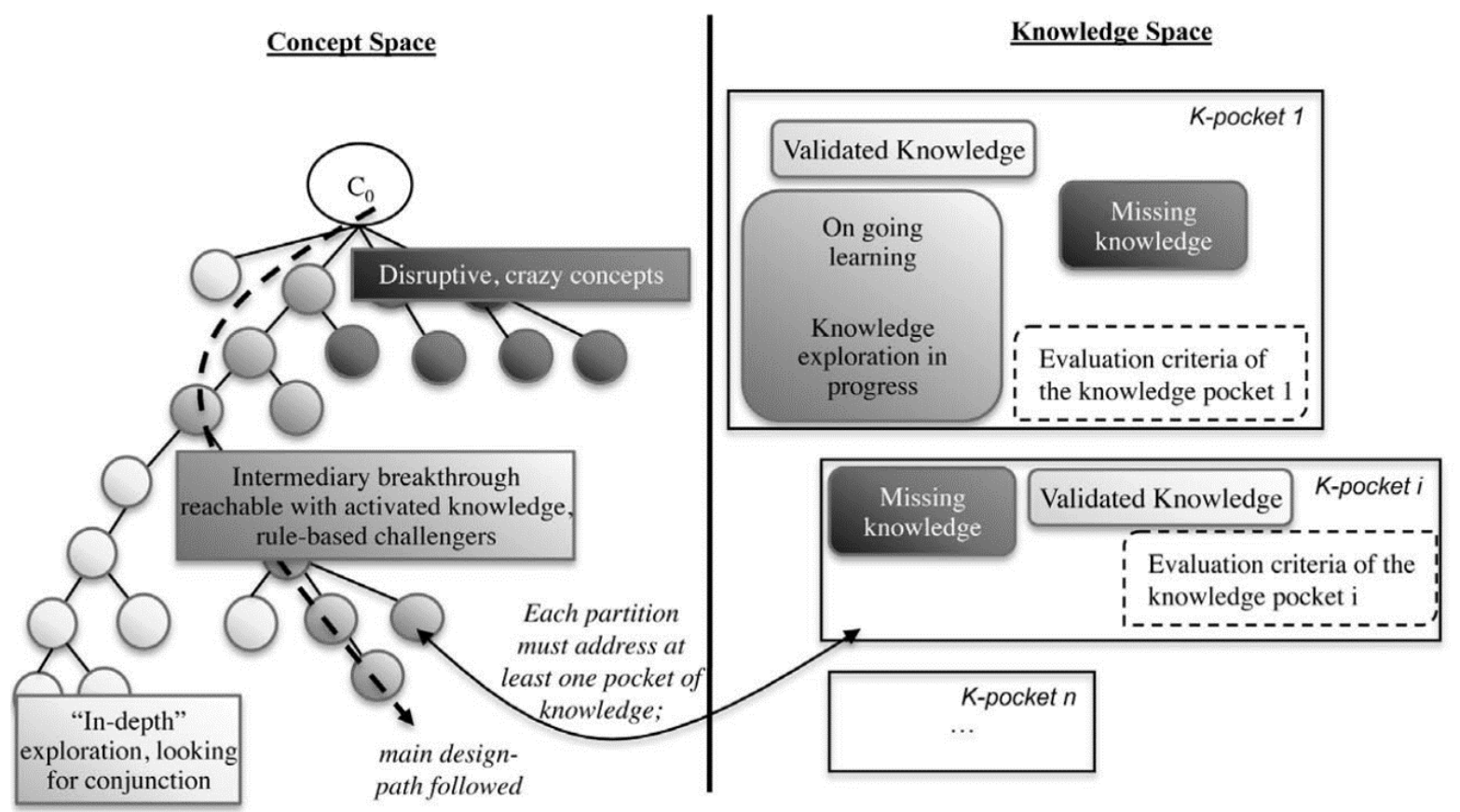

Fig. 3 The C-K model Agogué et al 2014, 


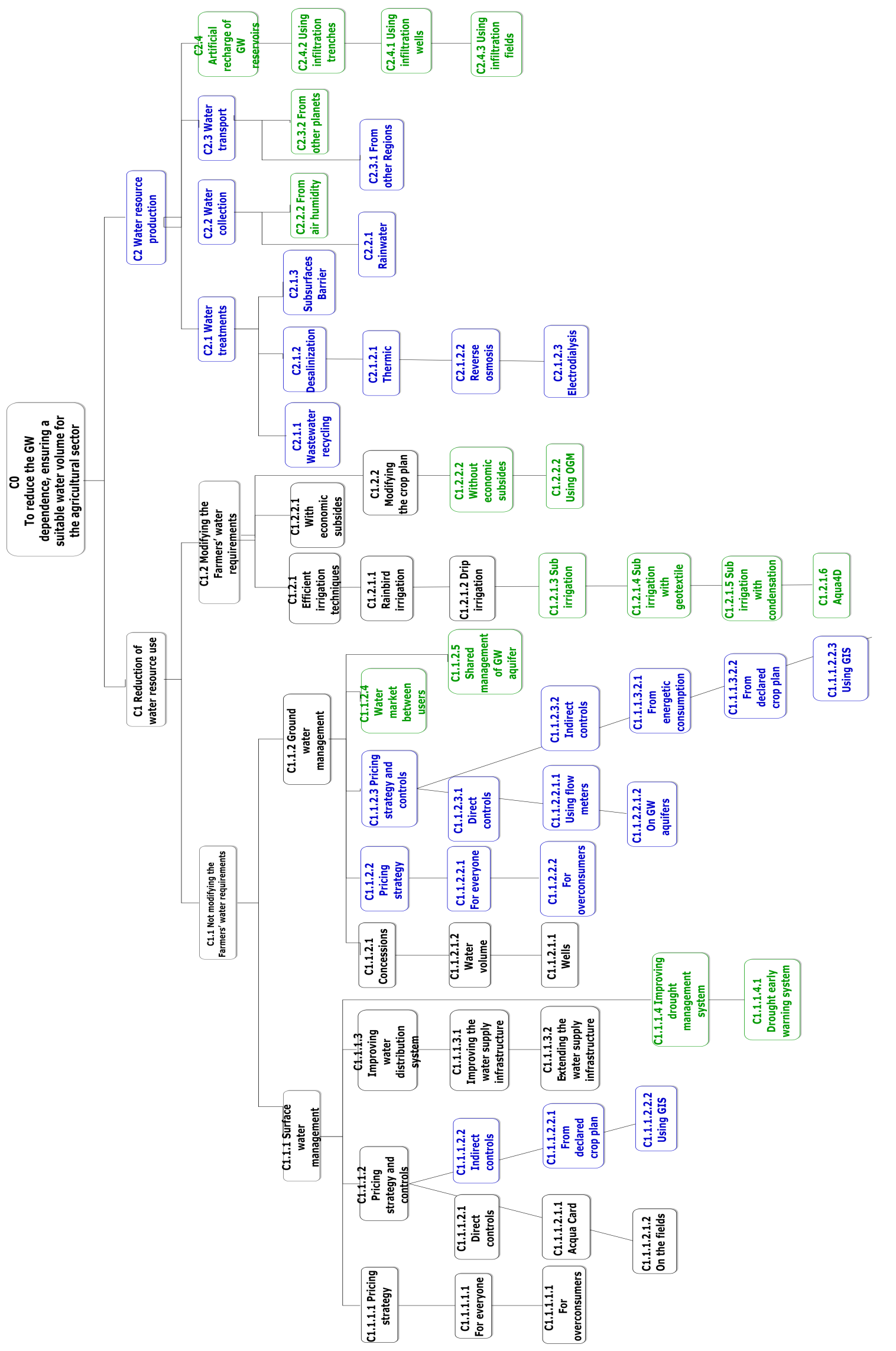

Fig. 4 The C-space showing all the policy alternatives generated 


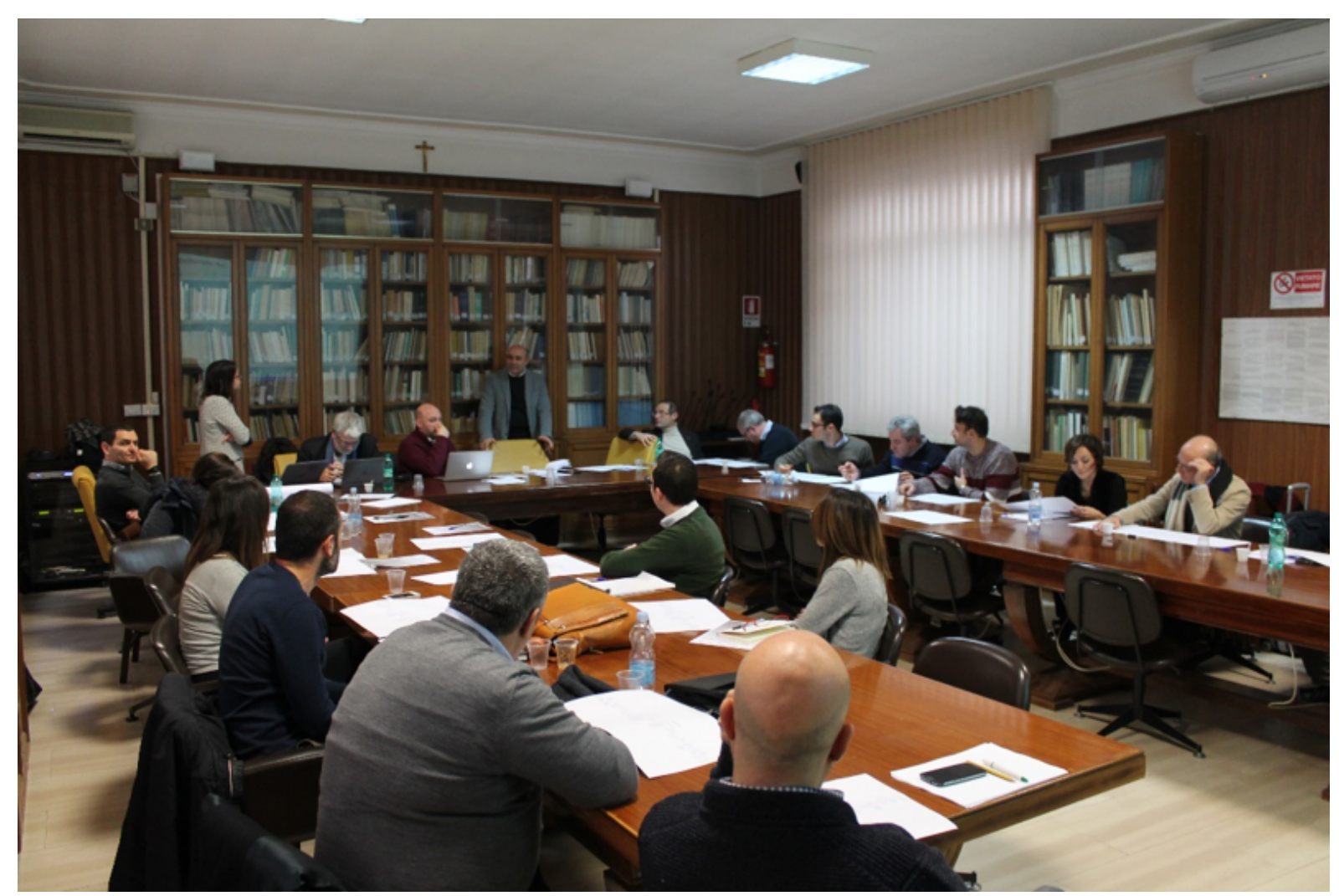

Fig. 5 The P-KCP one-day generative workshop hosted by the Consortium of Capitanata 

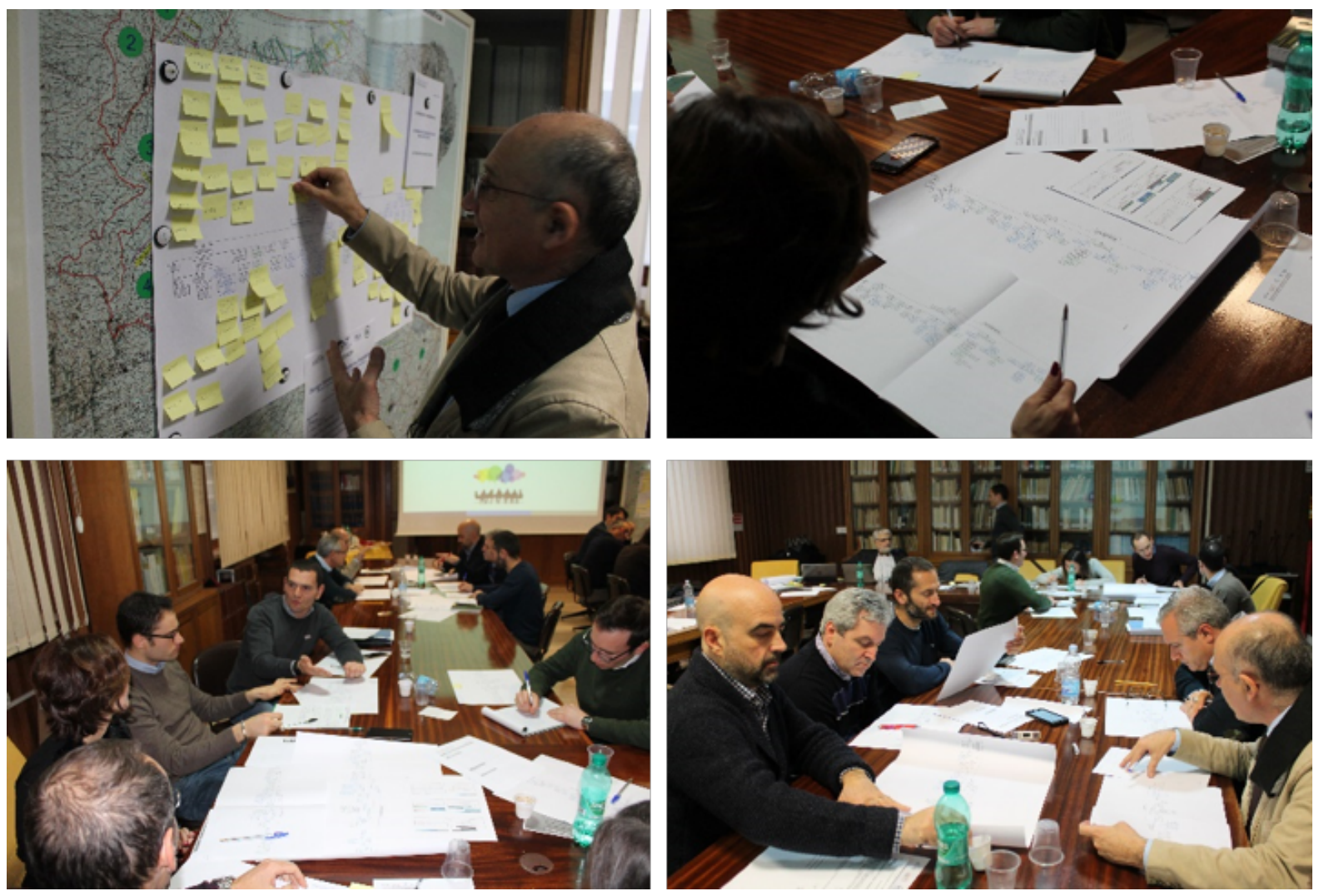

Fig. 6 Group activities during the P-KCP one-day generative workshop 